\title{
From pirates to subscribers: twenty years of music consumption research
}

\author{
Juan D. Montoro-Pons ${ }^{1}$, María Caballer-Tarazona ${ }^{1}$, and Manuel Cuadrado-García ${ }^{2}$ \\ ${ }^{1}$ Departamento de Economía Aplicada, Universitat de València, Spain. \\ ${ }^{2}$ Departamento de Comercialización e Investigación de Mercados, Universitat de \\ València, Spain.
}

Declaration of conflicting interests

The author(s) declared no potential conflicts of interest with respect to the research, authorship, and/or publication of this article.

\section{Funding}

The author(s) received no financial support for the research, authorship, and/or publication of this article.

\section{Data availability statement}

The data that support the findings of this study are available from the corresponding author upon reasonable request. 


\section{Authors' bios}

Juan D. Montoro-Pons is an associate professor at the University of Valencia. His current research interests include the quantitative analysis of digitization and information consumption, arts and cultural participation, and the creative industries. He has recently published on the structure of the music industry, consumer behavior in the cultural industries and informational asymmetries in digital good markets.

María Caballer-Tarazona is associate professor of Quantitative Methods at the Faculty of Economics, Universitat de València, Spain. Her main research interest covers topics as health economics, cultural economics, gender issues and behavioural economics. Her research results have been published in prestigious journals and international edited books. She has been research fellow at the Economics Department of the Bologna University (Italy) and taught in the Faculty of Communications and Economics in the University of Modena and Reggio-Emilia (Italy).

Manuel Cuadrado-García is an associate professor at the University of Valencia, Spain. His main line of research is marketing in the arts sector. He has undertaken research on consumer behavior, market research and diversity in performing arts (theatre, music and dance), cinema and visual arts. He has participated in numerous international conferences and published his work in several indexed journals. Guest editor in different academic publications as well as guest researcher at the London School of Economics, HEC Montreal, and Bocconi University, among others. He has also lectured in numerous seminars, postgraduate courses and conferences and has collaborated with different cultural organizations. 


\begin{abstract}
The last two decades have witnessed an increasing scholarly interest on music consumption. This interest can be explained, at least partly, to the relevance of music as a form of cultural consumption and the profound changes the sector has undergone. This paper performs a bibliometric analysis of the literature on music consumption research. In doing so, a database comprising 455 academic documents on the fields of business, economics and management, was reviewed following a systematic procedure. Through it we identify the intellectual roots and the methodological evolution of the field. Furthermore, text-mining was applied to analyze the themes included in the research agenda and their evolution. As a result, potential topics, approaches and methods for future music consumption research are proposed.
\end{abstract}

Keywords: bibliometrics, music consumer, recorded music, live music, text-mining, cocitation, bibliometric coupling, thematic analysis, Web of Science

\title{
1 Introduction
}

Music, as part of human society "for as long as there is recorded history", became marketoriented around the second decade of the twentieth century, as technological innovations (mainly radio broadcast and the phonogram) allowed composers and performers to reach out to mass audiences (Scherer, 2006). Since then, structural changes linked to supply disruptions (such as radio broadcasting, rock'n'roll, or, more recently, the digitization of music, see Tschmuck, 2003) have shaped consumer behavior and driven the ubiquity of music and music consumption.

Cross-country evidence shows that no other cultural manifestation has a wider appeal. Headline findings of arts participation surveys are consistent in revealing music as the most frequent form of cultural engagement. Results of the National Arts Participation Survey in Australia find that $92 \%$ of the population aged 15 or older listened to recorded music in 2019 (60\% listened to music on the radio or television at least once a week). ${ }^{1}$ Similar findings emerge in Spain, where the Survey of Cultural Habits and Practices in Spain 2018-2019 shows $87.2 \%$ of those aged 15 or older to listen to music in the 12 months prior to the survey ( $70 \%$ report listening to music once a day). ${ }^{2}$ In the US the Survey

\footnotetext{
${ }^{1}$ Survey by the Australia Council for the Arts. See https://www.australiacouncil.gov.au.

${ }^{2}$ See https://www.culturaydeporte.gob.es/portada.html.
} 
of Public Participation in the Arts, records the different ways that those aged 18 or older engage in the arts. In the case of music, results for 2017 are split into genres: jazz (20\% of adults claim to have listened over the past 12 months); Latin, Spanish and salsa (18.5\%); other genres, including rock, pop, country, folk, rap or hiphop (65.4\%); and classical music and opera $(20 \%){ }^{3}$

Being the most common form of cultural engagement, music has in the past two decades attracted scholars aimed at understanding the meaning and consequences of digital disruption and accelerated technological change with a special focus on consumption (Cameron, 2016; Sinclair \& Saren, 2019). However, few contributions attempt to take stock of the literature on the new ways of using and consuming music and their effect on markets. These include works dealing with live participation (Krueger, 2005; Connolly \& Krueger, 2006), analyzing piracy and copyright infringement (Peitz \& Waelbroeck, 2006a; Waldfogel, 2014; Liebowitz, 2016; Hill, 2007), or compiling the literature on the economics of music (Cameron, 2018).

Nevertheless, all these provide a partial account of the literature. Existing reviews either discuss specific aspects of music consumption or encompass music as one form of media consumption within a more general context. Saragih (2019) provides a review of 33 papers on co-creation in the music business, while Lowry et al. (2017) and Eisend (2019) undertake a meta-analysis of digital piracy (including but not restricted to music). Specifically, Lowry et al. (2017) review 257 studies on digital piracy classifying works into software piracy and media piracy, which combines music, movies and videogames. In the same line, Eisend (2019) analyzes 174 studies but only $17 \%$ of the papers reviewed are about music. From this discussion, it emerges that no systematic review on music consumption from a broad perspective has been attempted.

This paper fills this gap by systematically reviewing the intellectual structure and evolution of the literature on music consumption research (MCR) over the past two decades. Specifically, we seek to identify the advances and most relevant contributions in the field, its thematic evolution and the gaps in the literature that may help to shape the future research agenda.

In this context, the scientific production on music consumption and consumers cannot

\footnotetext{
${ }^{3}$ See https://www.arts.gov. As individuals may be classified into more than one genre, a lower bound for music listening is given by other genres' participation rate $(65.4 \%)$.
} 
be detached from the industry context. With the turn of the millennium a newly found scholarly interest on music consumption and music business focuses on the combination of digitization and the spread of disruptive information technologies swiftly embraced by consumers and incorporated as additional means to obtain, use and consume cultural content (Arli \& Tjiptono, 2016; Bhattacharjee et al., 2007; Cox \& Collins, 2014; Jain, 2008; Waldfogel, 2017). This has eroded the basis on which music is created, produced, marketed and distributed (Moreau, 2013), putting in the foreground the increasing relevance of creative resources and the creative industries in the information economy. Besides, scholars have analyzed digitization's broader implications. These include consumer behavior and ethics (Arli et al., 2015; Bonner \& O'Higgins, 2010), consumers' adoption of technology (Datta et al., 2018), sustainability and change in consumer services and new roles of stakeholders (Berlin et al., 2015; Gamble et al., 2017) among others.

This contribution takes stock of the existing literature on MCR to answer the following questions: (i) What is the intellectual structure of MCR? This implies identifying what theories, approaches and methods have been applied to identify the antecedents of music use/consumption, how are these approaches organized and what connections appear between them. (ii) What is the conceptual structure of the field? To answer this question we pinpoint the thematic areas treated by the research field and the links that emerge between them. (iii) Given what has been already achieved, what future directions are most promising? In this regard, gaps in the intellectual and conceptual structure of the field are explored to outline a future research agenda.

As already noted, the originality of the present work is justified by the absence of a systematic review in the field of MCR. In so doing it contributes to the literature in three ways. First, it reconciles the extraordinary amount of literature published on music consumption in business, economics and management in the past 20 years, providing an structured insight on the literature and the diversity of approaches underpinning it. Second, it pinpoints and classifies research topics according to their relative position in the research area and how embedded or disconnected they are from other topics within it. Finally, it spots gaps in the field and provides pointers to potential research avenues.

The paper is structured as follows. First, we outline the methodology discussing the procedures used with an emphasis on the search strategy that conforms the dataset used. 
Then, basic performance measures are used to describe the literature on MCR. Next, cocitation and coupling analyses follow. Fourth, co-word analysis and thematic maps are analyzed along with an insight on the conceptual evolution of the field. The paper closes with a discussion of the potential of unexplored approaches and lines of research and a conclusions section.

\section{Method and dataset}

\subsection{Systematic review}

Review articles contribute to the development of a given domain by identifying and synthesizing the relevant literature with the goal of pinpointing gaps in the scientific output and delivering potential avenues for research, delving into new contexts, theories and methodologies (Paul \& Criado, 2020). In short, as the advance of a scientific field is driven by past knowledge, review articles contribute to it by the critical evaluation of the extant research (Hulland \& Houston, 2020).

Paul \& Criado (2020) classify systematic review articles into four broad categories: domain-based reviews; theory-based reviews; method-based reviews; and meta-analytical reviews. Domain-based reviews can be further classified into structured reviews (such as Gupta et al., 2020), framework-based reviews (as in Paul \& Benito, 2018; Lim et al., 2021), bibliometric reviews (see for instance Randhawa et al., 2016), hybrid reviews (as Dabić et al., 2020), or reviews aiming at theory development (Paul \& Mas, 2019).

This paper draws on bibliometric analysis, which, through the study of the quantitative aspects of scientific communication (particularly citations), provides links between the research output a field produces whose structure can be analyzed (Mingers \& Leydesdorff, 2015). As Aria \& Cuccurullo (2017) note, "[bibliometrics] introduces a systematic, transparent and reproducible review process based on the statistical measure of science, scientists or scientific activity". Compared to other systematic review processes, bibliometrics provides objective criteria and measurable results to the analysis of a scientific domain.

However, from a critical standpoint, Paul \& Criado (2020) note that "bibliometric reviews do not deal with theories, methods, and constructs as much as they usually do 
with authors, affiliations, countries, citations and co-citations, etc". Notwithstanding, one should note that even if citations are at the core of bibliometric reviews, their links and structure allow to identify and cluster the different methods and theories of a research field (Jarneving, 2007). Besides, the approach implemented combines co-citation and coupling analysis with the thematic mapping of the field of MCR, providing additional insights into its structure (Cobo et al., 2011). In this regard, and given the multidisciplinary nature of MCR, bibliometrics can be a useful tool to grasp the alternative approaches the field has produced.

The strategy applied entails the use of three tools. First, we carry out a performance analysis on the field looking at basic descriptive summaries of the literature including geographical distribution, citations, author's productivity and outlets publishing MCR. Second, we map the intellectual structure of the field using co-citation and coupling networks. Note that the former reflects the consensus on an area about what references are relevant and the links between them (Small, 2004), while the latter provides a forwardlooking depiction of the current research (Jarneving, 2007). Third, we map the conceptual structure of the field. To do so, we use text-mining techniques and identify most frequent keywords and their links, which allows us to map the strength of the association between terms in textual data (Cobo et al., 2011; Aria et al., 2020; Randhawa et al., 2016). Furthermore, to track the evolution of the research and the themes that define it we use a longitudinal analysis by splitting the time period into two.

\section{$2.2 \quad$ Procedure}

The empirical strategy proceeds stepwise: (i) document selection; (ii) performance analysis; (iii) mapping of the intellectual structure of the field; and (iv) mapping of the conceptual structure of the field. A diagram summarizing the different stages of the review process and the actions taken is shown in figure 1.

First, to build the sample of music consumption studies we adopted a systematic process involving concepts identification, peer discussion, search and individual review (Randhawa et al., 2016). In doing so, we first collected bibliographical data from Clarivate Web of Science core collection (WoS), using the Social Sciences Citation Index (SSCI).

Prior to produce the database, language, time span, WoS categories and concepts to 
be searched were set. In this regard, the search involved published articles in English from 2000 to 2020 (both inclusive), within the WoS categories of economics, business or management. The search terms used to retrieve publications are shown in table 1 . Given that MCR is linked to technology-adoption and industry-related topics, a broad approach was pursued with search terms beyond music consumption being included in the query. Note this is justified as a preliminary search using only consumption-related terms excluded some high-impact articles on the effect of piracy on the recorded music industry. These manuscripts — although not including demand or consumption terms in their title, abstract or keywords - were unambiguously about consumer behavior and new consumption patterns in the music market. Through this strategy, an initial list of documents to be screened and fine-tuned through individual research and peer discussion was retrieved.

It should be noted that WoS restricts the documents retrieved to articles published in SSCI-indexed journals, explicitly excluding books and book chapters. Alternatively, a free service such as Google Scholar (GS), which might be the first choice when conducting academic literature searches, could have been considered to broaden the search coverage. However, the use of GS in bibliometric analysis is not without drawbacks: research has pointed to the automated inclusion of documents in GS through web-crawling (Bar-Ilan et al., 2007) or the lack of an indexing strategy (de Winter et al., 2014) as a source of errors and/or inconsistencies. Namely, the unconstrained nature of the content that GS indexes (Aguillo, 2012) and the lack of a quality control process (Harzing \& Alakangas, 2016) makes it a less attractive source that further complicates the document selection strategy.

The search strategy resulted in 932 documents that were individually reviewed by the authors using the following guidelines: papers focused on the consumption of recorded and live music were included; those dealing with the organization of music supply were included only when explicitly taking music consumption into consideration; manuscripts focused on music as an additional element within the consumer experience, servicescape or the impact music has on people's attitudes or emotions were removed. By pooling the three evaluations and after discussion 455 formed the final dataset. The process took place from mid May to mid June 2020. 
Second, descriptive statistical summaries resulted in the performance analysis of the field. In this respect, measures of scientific productivity allowed to identify authors, countries and journals that stand out in the MCR field. Additional measures of influence are produced through citation analysis both inside and outside the field: general and local (or within-sample) citations are provided to approach the impact of the articles.

Third, the intellectual structure of MCR was spatially mapped through co-citation and bibliographic coupling. Both techniques allow to identify concurrent research lines and to highlight different theoretical and methodological approaches. However they differ in how they tackle this inquiry. Co-citation links documents that appear together as cited references in the articles that form the database (Small, 1973). By contrast, coupling looks at citing papers: two papers are said to be bibliographically coupled if at least one cited source appears in the reference lists of both papers (Jarneving, 2007; Ruggeri et al., 2019). The more two papers are cited together the stronger their co-citation. Likewise, the more the number of cited references two papers share, the stronger their coupling. It is through the links and strength of the ties formed between papers that different intellectual approaches (clusters or communities in the network) are detected.

Differences between co-citation and coupling lie in the different orientation of the approaches. Co-citation can be seen as a backward-looking technique, as it looks at references that are commonly cited together, whereas bibliographic coupling, by looking at the citing papers (that share references) is a forward-looking strategy. In short, cocitation tends to favor well-established contributions, whereas coupling allows to discover the intellectual boundaries of the field of inquiry (Ruggeri et al., 2019).

Fourth, the conceptual structure of MCR was mapped through co-word analysis, a content analysis technique that exposes the association between terms in textual data and its strength (Callon et al., 1983; Courtial, 1989; Kostoff, 1993). It draws on a word co-occurrence matrix to map basic information items into a network. The procedure can be applied to any piece of textual information, such as keywords, titles or abstracts. The resulting network links words (i.e. common text elements or concepts) that appear in documents together. The more the number of documents in which two terms appear together, the stronger the equivalence or association between them (Callon et al., 1991). This allows to classify textual items and to identify the themes MCR literature has produced. 
Furthermore, a thematic map is produced using metrics of centrality (relevance of textual items within the field) and density (strength of the internal ties between items that form a theme), allowing to classify the potential of the identified themes (Cahlik, 2000a,b; Cobo et al., 2011; Courtial \& Callon, 1991).

All the bibliometric analysis was performed with open-source software (R Core Team, 2019). Specifically, the $R$ libraries bibliometrix (Aria \& Cuccurullo, 2017) and $i$ Graph (Csardi \& Nepusz, 2006) were used.

\section{Performance analysis}

Performance analysis aims at describing and assessing the productivity and the centrality of the different actors of the field under scrutiny (Cobo et al., 2011; Aria \& Cuccurullo, 2017). To this end the database is analyzed from four perspectives: (i) through basic statistics and numerical summaries to describe the field and its overall evolution; (ii) looking at the geographical distribution of the scientific output and its impact; (iii) ranking the outlets where research is published; and (iv) through the analysis of the most influential documents in the dataset.

First, basic descriptive statistics of the document collection are displayed in table 2 . The dataset includes 455 documents from 801 authors published in 141 journals spanning from 2000 to 2020. Over this period, the dynamics of the scholarly output reflects a growing relevance of MCR with an annual growth rate of $5.18 \%$. Indeed, the number of articles goes from 4 in 2000 up to 45 in 2019 showing the increasing interest of researchers in the field. This scientific production is unevenly distributed: splitting the time interval into two (roughly) equal periods, $24 \%$ of the output is produced in the first period (20002009), while $75 \%$ is produced in the second (2010-2020).

All documents received 9985 citations, with mean citations per document being 21.95, and median citation count being eight. Looking at authorship to account for the size of research teams an average of 0.567 documents per author was found. Moreover, only $23.3 \%$ of the production is single-authored and the average number of co-authors per document is 2.24. Alternatively, the collaboration index (mean number of authors per multi-authored document) is equal to 2.03. At any rate, scholarly cooperation is shown to be the most usual form of involvement in the field. 
Second, table 3 shows the top ten countries by production and impact in the field of MCR. USA is the leading country in terms of output (153 articles representing $33.85 \%$ of the total) and impact (4,801 citations). Next come United Kingdom, France, Germany and Australia in terms of output, while Canada and China replace France and Australia in terms of impact. Note that average citations provide an output-corrected measure of scientific impact and shows an alternative ranking in which Israel, not being among the most productive countries, gets the greatest average citations per paper.

Third, the analysis of the sources that publish in the field of study suggests a rather diverse and multidisciplinary approach (table 4). While journals in economics and marketing top the list, the diversity of approaches is reflected on the mixture of the outlets that published most of the research. This includes broad-scope journals (e.g. European Journal of Marketing or Journal of Business Research ) as well as more specialized ones (Information Economics and Policy or Journal of Business Ethics). In this regard, it is noteworthy that only two of them are specialized in the research field of culture and the arts: Journal of Cultural Economics and International Journal of Arts Management.

Fourth, using citations to proxy impact of scientific output, the most influential papers are reported in tables 5 -global citations, i.e. all citations for documents within the collection - and 6 - local citations, i.e. how many times a document in the collection has been cited by another document in the collection. Note that, unsurprisingly, most papers appearing in both tables have been published before 2010 suggesting that the number of citations a document receives could somehow be related to its publication year. Looking at global citations, it is noticeable that all of the top-cited papers have been published in high-impact generalist outlets: four of them in the Journal of Consumer Research while the rest in outlets not ranked in table 4 such as Journal of Services Management, Journal of Political Economy or Journal of Law and Economics. The background of the research in this group (see category in table 5) shows a balanced mix of economics, business and management. The themes explored are related to identity and self-expression through music (Belk, 2013; Berger \& Heath, 2007) and the disruption brought about by the digitization of music. This includes the determinants of file-sharing as a new form of music consumption (Chiou et al., 2005), its sociological foundations (Giesler, 2006) and its impact on markets (Oberholzer-Gee \& Strumpf, 2007; Rob \& Waldfogel, 2006; Zentner, 
2006). Moreover, the co-creative roles of consumers in music markets through financing of projects (Ordanini et al., 2011) and content-creation (Dhar \& Chang, 2009), or the dynamics of the structural change in the music market (Giesler, 2008) are also explored.

Looking at local citations (table 6) the diversity of backgrounds and topics recedes, with seven of the top-ten papers within the scope of economics. As for diversity of topics, all ten papers are linked to piracy or the assessment of its impact on music markets (Bhattacharjee et al., 2007, 2006b; Liebowitz, 2008; Mortimer et al., 2012; Peitz \& Waelbroeck, 2006a,b). In this respect, it becomes apparent that while a significant part of MCR borrows from the literature on copyright infringement and its effects, the impact of MCR outside the literature on music consumption includes but goes beyond topics related to piracy.

\section{Intellectual structure of MCR}

The intellectual structure of MCR is mapped through citation analysis, which employs citation links and counts to measure the similarity between documents. As mentioned, two techniques are used: co-citation analysis and bibliographic coupling. Co-citation links are established for references cited together, while bibliographic coupling connects citing documents (Aria \& Cuccurullo, 2017). Both produce a network of publications and the links between them from which a set of communities or clusters emerge. These are to be understood as groups of references that structure the intellectual base of the different subfields (Cobo et al., 2011).

The process involves two steps: normalization of the network of cited (co-citation) or citing (coupling) references, and community detection. As for the former, note that the distribution of the number of ties that connect publications within the network is skewed, with a relatively small share of highly cited papers attracting most edges compared to less popular publications. The normalization of these differences is performed through association strength (Eck \& Waltman, 2009).

Community detection identifies the intellectual structure of the field. It draws on numerical techniques that aim at maximizing the modularity of the resulting partitioned network. The small local moving algorithm has been recently proposed as an efficient method to detect clusters in large and very large graphs (Waltman \& Van Eck, 2013). It also performs better than other alternative and well-known methods (such as the Louvain 
algorithm, see Emmons et al., 2016). This work uses a modified version known as the Leiden algorithm (Traag et al., 2019).

Šubelj et al. (2016) suggest criteria to assess the clustering of bibliometric networks. First, clustering should produce stable results with groups of similar size. In this review, default options for the algorithms were used and these were initiated with different random seeds to analyze the consistency of the results. Overall, the number of clusters was robust over runs of the algorithm and when small clusters emerged (particularly in the coupling analysis) the number of publications these contained were marginal (in most cases isolated nodes with one publication). Second, and most important, resulting clusters should make sense. In this review, as it is discussed next, publications clustered together are connected by theme, approach and/or methodology.

\subsection{Co-citation analysis}

We start by looking at what contributions have had a most significant influence in the shaping of the field of MCR and how they define specific research lines. We restrict the analysis to documents with the most impact on the field by subsetting the dataset to include those in the top quartile of the citation distribution (23 or more citations). This generates a set of 115 focal papers.

Figure 2 shows the co-citation network. The size of nodes is proportional to their degree and labels appear only for contributions whose centrality in the network is in the top decile. The network shows a core of articles that broker the connections with agglomeration of nodes in the periphery. The community detection algorithm has detected seven clusters of which three seem to carry more weight in connecting nodes (i.e. cited references). It can be seen that the centrality of the nodes in these three clusters is spread among a larger number of papers. The remaining four clusters concentrate the centrality measure in fewer references. In any case, the relevance of these papers lies in the ability to connect different research lines. Next we discuss these in detail.

Cluster 1: Information, intellectual property and infringement. Cluster one defines a research subfield focused on information goods, intellectual property rights and the impact of piracy. The institutional context of recorded music consumption is laid out by analyzing copyright from a theoretical (Landes \& Posner, 1989; Novos \& Waldman, 
1984) as well as an applied perspective (Ku, 2002; Liebowitz \& Watt, 2006). The former frames the economic discussion on information goods and copying (Johnson, 1985; Varian, 2000, 2005) and introduces the debate on the potential positive effects of infringement: indirect appropriability (Liebowitz, 1985), network externalities (King \& Lampe, 2003; Reavis-Conner \& Rumelt, 1991; Takeyama, 1994), bundling (Bakos et al., 1999) and sampling (Gopal et al., 2006). These offset the magnitude of the substitution effect between original and copies and lead to a theoretically ambiguous impact of file sharing (and copyright infringement in general) on revenue and/or profits. Against this background, empirical works aim at measuring the impact of piracy and file-sharing in the music industry. Documents in this cluster find that the substitution effect dominates, both when using cross-country data (Hui \& Png, 2003; Liebowitz, 2006) and individual-level data (Rob \& Waldfogel, 2006; Zentner, 2006) mostly from an econometric perspective. Nevertheless, there is also an early attempt at analyzing survey data to explore alternative digital business models (Bhattacharjee et al., 2003).

Cluster 2: Consumer behavior. This cluster finds its intellectual roots in sociology and methodologically draws on ethnographic and case studies. The key contributions influencing the sub-field deal with the organizational function social networks serve (Granovetter, 1973), identity and self-identity as a social and collective process (Firat \& Venkatesh, 1995; Giddens, 1991), the consumption of symbols as a means of self-expression (Belk, 1988; Schouten \& McAlexander, 1995; Ahuvia, 2005) and the influence of tribes and subcultures and the role of collective consumption (Cova et al., 2007; Maffesoli, 1995; Muniz \& O'guinn, 2001; Schau et al., 2009). In brief, all these contributions delineate how markets and social relations interact in the construction of the subject, i.e. the postmodern consumer. Finally, a few manuscripts analyze music consumption, such as the role that technology has on new consumption practices (O'Hara \& Brown, 2006) and the new business models it generates (Fox, 2004). In addition, the changing meaning of music consumption that digitization has brought about and the function physical consumption serves as a signaling device for music engagement and knowledge (McCourt, 2005; Styvén, 2010) are also analyzed. 
Cluster 3. Music industry organization and strategic approaches. The third cluster provides the background for the subfield where industrial economics and strategic management overlap. The central references find its roots in the neo-institutionalist approach to the firm and its evolutionary nature (Nelson \& Winter, 1982; Williamson, 1975, 1985). Works in this subfield include a resource-based view of the firm, emerging from the strategic management perspective (Wernerfelt, 1984), that informs the literature on firm-specific assets as the source of competitive advantages and, hence, value-creation and value appropriation (Barney, 1991; Dierickx \& Cool, 1989; Peteraf, 1993; Teece et al., 1997). In parallel, a general discussion on the organization and economic geography of the creative industries (Caves, 2000; Scott, 2000; Vogel, 1998) frames their project-based nature and leads to the strand of the literature on learning, the informal relations that such projects foster, knowledge transfer and the emergence of communities of practice (DeFillippi \& Arthur, 1998; Ekinsmyth, 2002; Grabher, 2002; March, 1991; Wenger, 2000). Finally, specific references to the music industry are also included in this cluster: on the search behavior driving competitive dynamics and how this influences business models and organizational forms (Huygens et al., 2001), the role that market concentration has on innovation and diversity (Lopes, 1992) or the debate of flexibility and the links between major and small record labels (Hesmondhalgh, 1996).

Cluster 4. Embracing disruption. While this cluster is mostly related to the marketing literature, it also includes empirical works on copyright infringement in music that, unlike those in cluster 1, find no impact on sales (Oberholzer-Gee \& Strumpf, 2007), suggest alternative explanations to the plummeting of music sales (Stevans \& Sessions, 2005), or cast doubts on the effectiveness of strategies to contain file-sharing (Bhattacharjee et al., 2006b). Digital distribution of music fits the theoretical framework provided by the service-dominant logic for marketing (Vargo \& Lusch, 2004, 2008). It allows for the incorporation of value co-creation (Grönroos, 2008, 2011) and the shift to experiences (Prahalad \& Ramaswamy, 2004) to understand the role of user-generated content and user-led innovation in media (Banks \& Deuze, 2009) and the integration of consumers as content creators in social media marketing strategies (Akar \& Topçu, 2011). Furthermore, music fan behavior in digital channels (Beaven \& Laws, 2007) and their involvement from a critical standpoint (Baym \& Burnett, 2009) are also analyzed. 
Digital music and file-sharing as an alternative for music consumption raise new questions (Huang, 2005) as well as shed light into consumer behavior. Specifically, the implications of digital rights management (DRM) and the potentially positive impact on demand of distributing DRM-free music by shifting pirates into paying consumers (Sinha et al., 2010) or the likelihood of consumers' adoption of online music services (Kunze \& Mai, 2007) are explored.

Cluster 5. Marketing the arts. Works in this cluster are mostly applications of marketing to the arts, including some general results related to the formation of tastes and preferences and the economics of the performing arts. Regarding preferences, results show the stability of consumers' tastes for popular music after early adulthood (Holbrook \& Schindler, 1989), which underscores nostalgia as a relevant source of consumer preferences (Schindler \& Holbrook, 2003). Furthermore, this strand of the literature acknowledges the sociological notion of homology to explain observed cultural behavior: the position of consumers in the social structure (i.e. class membership) determines cultural participation (Bourdieu, 1984).

Where tensions between arts and markets pop up, "arts marketing should primarily aim to support and reinforce the artistic functioning of artworks" and focus on "the artistic experience as the core customer value", with art consumers playing the role of co-producers in the process (Boorsma, 2006). This tension highlights the "intellectually debilitating opposition" between arts and marketing, which can be overcome through the analysis of the different meanings embedded within arts marketing (Bradshaw, 2010). Finally, works that set forth specific applications to performing arts (Assassi, 2007; Caldwell, 2001) and museums (Baumgarth, 2009; Camarero \& Garrido, 2008) as well as general pricing strategies (Kim et al., 2009) are also included.

Cluster 6. Information economics. This cluster is a mixture of information economics and structural equations methodology. With regards to the former, works acknowledge the impact that the network economy emerging from the spread of information technologies (Shapiro \& Varian, 1999) has had in both supply — through the organizational transformation many sectors have undergone (Brynjolfsson \& Hitt, 2000) - and demand —reducing consumers' search costs, therefore increasing market efficiency (Spulber, 1996; 
Bakos, 1997). In addition, methodological issues related to structural equations (Fornell \& Larcker, 1981; Anderson \& Gerbing, 1988; Hu \& Bentler, 1999) and the application to music markets (Moe \& Fader, 2001) are considered.

Cluster 7. Consumer innovativeness and ethical consumption. This final cluster covers topics on consumer behavior beyond those found in cluster two. Specifically it includes works on the diffusion of innovations and the related topics of users acceptance of innovations, innovations adoption and innovativeness in consumption (Davis, 1989; Hirschman, 1980; Mahajan et al., 1990; Rogers, 2003; Venkatesh et al., 2003). Ethical consumption is also part of this cluster: the introduction of ethical foundations adds a new dimension to exchanges (Gundlach \& Murphy, 1993) and allows to identify the ethical constraints consumers face in the sharing of digital music (Levin et al., 2004; Taylor, 2004).

Table 7 summarizes the findings of the co-citation analysis. For each of the seven clusters it includes their intellectual background, a short-list of themes and the top five references by their centrality in the resulting network (i.e. number of links to other references in the network). Based on it, it can be concluded that MCR draws on four intellectual strands: economics, sociology, management and marketing. However, while sociology and management reproduce monolithic approaches and lines of research, economics and more significantly marketing seem to mix with different fields of inquiry to produce a hybrid intellectual structure.

\subsection{Bibliographic coupling}

Bibliographic coupling is performed on the full document collection to provide an account of the research front in MCR. To track its evolution, the database is split into two periods. Summaries of key findings are shown in table 8.

\subsubsection{Period 2000-2009}

This period's scientific output comprises 116 papers, which are grouped in 9 clusters, although only three are large enough. ${ }^{4}$ Figure 3 plots the resulting network. In this period MCR is mainly about the effect that digitization and the emergence of technologies

\footnotetext{
${ }^{4}$ Irrelevant clusters are isolated nodes in the network.
} 
have on the traditional business model of the music industry via observed changes in consumers. A great share of the output deals with the analysis of piracy and file sharing as new channels of accessing music (and other information goods) that increase consumption opportunities. The topic has been analyzed from a diversity of approaches: economics (mainly the impact of copyright infringement on sales and/or profits, i.e. substitution effects, as well as potential positive, or sampling, effects), management (such as the dynamics of innovation, value creation and business models in the industry with piracy) or marketing (e.g. marketing strategies under copyright, infringement and misbehavior, or consumer behavior under ethical constraints). While piracy is the central topic under scrutiny, theoretical and methodological approaches are diverse.

Cluster 1. Piracy and file-sharing. The digitization of music, advances in online technologies and bandwidth availability open new channels of music consumption impacting on the music industry as they unfold the potential for piracy and file sharing. Papers included in the first cluster, address the issue mostly from an economic approach, focusing on the impact of piracy and file sharing through the use of quantitative methodologies (Oberholzer-Gee \& Strumpf, 2007; Bhattacharjee et al., 2007). Specifically, we find papers that model the propensity to pirate, identifying traits that characterize copyright infringers (Fetscherin, 2009; Chiang \& Assane, 2007), their seek for variety (Adomavicius et al., 2015), or the relationship between the intention to illegally download and legally purchase music (Wang et al., 2009). Furthermore, ethical dimensions (as elicited by users) or the rationalization of misbehavior (Shang et al., 2008; Harris \& Dumas, 2009; Regner \& Barria, 2009) are considered.

New technological possibilities have an impact on the institutional setup, such as copyright, which raises questions about the effectiveness of its enforcement both from the individual (Bhattacharjee et al., 2006b) and the national level (Montoro-Pons \& CuadradoGarcía, 2008), as well as its functions and efficiency from a theoretical perspective (Varian, 2005; Khouja \& Park, 2007; Liebowitz \& Watt, 2006; Liebowitz \& Margolis, 2009; Jain, 2008).

Cluster 2. Marketing and business strategies. A second cluster includes papers that address the analysis of piracy and file sharing from management and marketing 
approaches. Thus, we find papers, which analyze specific marketing strategies ( $\mathrm{Tu} \& \mathrm{Lu}$, 2006; Plouffe, 2008), business models (Huang, 2005) or supply chain structures (Rabinovich et al., 2003; Song et al., 2009) most suited to a context in which contents can be easily shared and used. Other authors look into both the motivations that underlie the decision to engage in music piracy from a marketing perspective (Coyle et al., 2009; Ouellet, 2007) as well as the identification of factors that can foster legal consumption under this new context (Cowart et al., 2008; Kwong \& Park, 2008; Chu \& Lu, 2007).

Novel consumption alternatives bring new factors constraining and/or defining consumer behavior. Content accessibility makes search behavior (Zhang et al., 2006) or the assessment of the quality of cultural objects (and its link to appeal to audiences, Dhar \& Chang, 2009; Holbrook et al., 2006) undertakings of utmost importance. Additional elements that the literature stresses are those related to the collective experience of cultural consumption and identity and self-expression, which are intimately entangled with music participation (Earl, 2001; Goulding et al., 2009).

Cluster 3. Music production, innovation and value creation Despite its relative heterogeneity, the third cluster revolves around the effects of the digital context and new consumption means on the industry, including music production, innovation and value creation. In this regard, the literature includes papers on the effect of new distribution channels on music production (Mol et al., 2005; Power \& Hallencreutz, 2007), the role of global commodity chains (Power \& Hallencreutz, 2007), entry barriers and the challenge that file-sharing poses to the supply chain by changing entry barriers (Lewis et al., 2005; Lorenzen \& Frederiksen, 2005), the temporary and project-based nature of some organizations in the industry and the social and productive networks they foster (Sedita, 2008), or how the new market organization and business model has an impact on innovation (Tang, 2005). Furthermore, in a market with an abundant supply of releases, consumers lack the necessary information to know about the actual choice set. In this respect, a few papers analyze the industry context as the set of market organizations that, by connecting consumers and artists, select the supply and manage innovation (Mol \& Wijnberg, 2007; Hirsch, 2000; Thompson et al., 2007). 


\subsubsection{Period 2010-2020}

This period includes 346 articles that were grouped into 7 clusters although, again, only three are substantially large (see figure 4). The topics covered within the papers of this period respond to the rapid changes in users' habits and providers' strategies. After the consolidation of the structural changes the digitization of music information technologies brought about, scholars shift the focus to the study of the new potentials.

Cluster 1. Social networks in the digital era. The first cluster groups papers on the new potential the digital environment and digital social networks provide. Specifically, new digital media increase the diversity of organizations that intermediate (or disintermediate) cultural markets. In this regard, the possibility of interacting with consumers and creating links is a fundamental factor of artists' success, economic benefit and marketing practices in the digital era (Choi \& Burnes, 2017; Gamble \& Gilmore, 2013). The Internet fosters the emergence of fan/celebrity ties that affect the willingness to buy music (Daellenbach et al., 2015) or, through the proliferation of music blogs and sites, creates platforms that generate opinions and assessment having a huge influence on artists' itinerary, especially on new ones (Steininger \& Gatzemeier, 2019). To some extent these define markets as networks of actors who shape acceptable practices. Thus, while the possibility of opinion and assessment by the public can be a source of loyalty, it can also penalize those new artists who deviate from (genre) authenticity rules (Mattsson et al., 2010). In short, such market configurations allows actors to define market-restricting practices (Hietanen \& Rokka, 2015).

The new digital context provides new possibilities for co-creating value between consumers and music industry through the media. Social media allows to establish relationships and interact with fans in order to co-create value and vitalize the collective consumption, engagement, and participation. This scenario of communication and socialization favors the transmission of emotions and self-extension through music consumption (Belk, 2013; Wood \& Kinnunen, 2020). It also emphasizes its symbolic nature through specific patterns of behavior such as imitation (Guerzoni \& Nuccio, 2014) or technology adoption (Nokelainen \& Dedehayir, 2015) which can also be a means of self-expression (Miquel-Romero \& Montoro-Pons, 2017). 
Cluster 2. Streaming and live music. Cluster 2 classifies research on new digital consumption means and live performances as alternatives of CD sales for the key actors in the sector. Streaming is taking off and hence drives new developments in the field, such as the innovativeness, discovery and diversity in music consumption of streaming users (Datta et al., 2018) or users' social behavior, i.e. participation in the online community, that affects their willingness to become premium subscribers and hence impact on the sustainability of the business model (Oestreicher-Singer \& Zalmanson, 2013). The latter is extensively discussed in this group of contributions. Koh et al. (2019) raise the need to review the licenses to download and buy digital music, in order to consolidate the digital music purchase and subscription to streaming platforms, whereas Sinha et al. (2010), Handke et al. (2016) or Klein \& Slonaker (2010), look into the role of digital right management (DRM) and the need to reduce prices, in order to transform pirates into legal consumers of digital music. A somewhat related issue is that of the unbundling of music (from albums in the physical world to songs in the digital realm) and its negative impact on revenue (Elberse, 2010).

Within this period, the decline of recorded music sales has been matched by an increasing relevance of live performances. One strand of the literature analyzes whether consumers consider live and recorded music consumption as complements, and the evidence so far suggests that consuming recorded music increases the likelihood of live music attendance but not the other way around (Montoro-Pons \& Cuadrado-García, 2011). Furthermore, the estimated cross-effects between live and recorded music consumption have been found to be asymmetric and mediated by developments in the industry such as unbundling or the decline of piracy in most markets (Papies \& van Heerde, 2017).

Cluster 3. Piracy revisited. Research on piracy and file sharing is still on the agenda, as the third cluster of articles shows. However, the focus has been shifted to the development of business models that allow to incorporate consumers into legal consumption: digitization and the Internet are no longer a threat but an opportunity. Early in this period we find research on the positive impact of ad-based models to attract users who otherwise refrain from the legal market (Papies et al., 2011).

Two strands of research are found in this group of documents. First, on the potential substitution effects that streaming might have on piracy and other legal channels for music 
consumption. As for piracy, the evidence in this group is mixed with findings that suggest that streaming is not (yet) a substitute for piracy (Borja \& Dieringer, 2016), whereas other papers find that specific consumers' segments could be incorporated into legal consumption (Sinclair \& Green, 2016). Even though there is evidence of streaming cannibalizing other legal channels, its net effect has been found positive for the industry (Wloemert \& Papies, 2016; Aguiar \& Waldfogel, 2018).

The second line of research aims to characterize the intention to consume music both illegally and legally. Perceived usefulness and enjoyment are found to determine the adoption of music streaming services (Hampton-Sosa, 2019). Research using university students suggest that illegal consumption is explained through the social learning environment, attitudes and subjective norms or culture (Wang et al., 2011; Dilmperi et al., 2017; Reardon et al., 2019). However, one should note that the reliance on university students' surveys could lead to a selection effect and, in any case, results need not apply to the overall population.

\section{Conceptual mapping of MCR}

\subsection{Text mining and co-occurrence of keywords}

The building block of the conceptual mapping strategy is co-word analysis, which draws on a word co-occurrence matrix to spatially map information items into a network. Nodes are pieces of textual information and edges connect nodes that appear together. The equivalence between two terms is based on the number of documents in which the two terms appear together (Callon et al., 1991). A network is then produced and its nodes are clustered together giving rise to themes.

To generate the network three decisions are made. First, as the research agenda evolves over time, so do research topics and their connections. In order to track this dynamics, we split the database in two, with 2010 the cutoff year. Second, we choose WoS keywords plus field as the object of the textual analysis. These are the outcome of a WoS proprietary algorithm that reduces the idiosyncrasy of author's keywords by searching across disciplines for all the articles that have cited references in common (Garfield, 1990a,b; Garfield \& Sher, 1993). As a result, this process reduces the observed variability in documents' 
keywords. Third, to render a manageable co-word analysis (and thematic mapping) we use the top quartile by citations. In so doing, we assume that the most cited or focal papers drive the conceptual structure of the field. Furthermore, and for the sake of clarity, only the most frequent 150 extracted terms are included in the analysis.

\subsection{Thematic maps}

A thematic map draws on the co-word network to classify clusters of terms (i.e. themes) according to two metrics (Callon et al., 1991). The first one, centrality, measures the strength of the ties of one theme (i.e. cluster) with other themes. Namely, it measures the degree of interaction of a theme with other themes. Cobo et al. (2011) regard it as a measure of how important a theme is within the analyzed research field: the more the links that tie a theme with other themes, the more integrated it is within the research field and hence its centrality. The second one, density, measures the strength of the ties within the cluster, i.e. how dense the network between the terms that form a theme is. As Cobo et al. (2011) note, this is a measure of how developed a theme is.

Thematic maps plot clusters of terms in the centrality-density space. The position a theme occupies in the map allows us to identify four types of topics (Cahlik, 2000b; Callon et al., 1991):

1. The upper-right quadrant defines themes with high density and high centrality. Themes in this area are developed and important to the research field and are identified as motor themes.

2. Themes in the upper-left quadrant have high density and low centrality. This encompasses marginal (or isolated) themes to the field, which are well developed (strong internal ties) but weakly connected to other themes.

3. Themes in the lower-left quadrant exhibit low density and low centrality. This is the case of themes that are not developed and have weak external ties with other themes in the research field. These could be either declining or emerging themes.

4. Lower-right quadrant themes show low density and high centrality. Here we find themes that are important (well connected with other clusters in the field) but not fully developed: basic and transversal themes. 
Figures 5 and 6 display the clusters of the co-occurrence networks in a thematic map for the two periods under consideration. The size of each cluster (circles in the map) is proportional to the frequency of its top keyword. To improve readability only five keywords are shown. Next, we analyze these starting from the rightmost cluster in the upper-right quadrant in a counterclockwise fashion. Terms included in each theme are stressed in italics. Examples of papers that illustrate a theme are included but note that papers may overlap theme boundaries.

\subsubsection{Period 2000-2009}

The first theme in figure 5, the one with the highest centrality and density, defines a research line around adoption of technology in the commerce of services. Here we find other central terms such as purchases, impact, quality and satisfaction as central, which suggests a predominantly consumer-centered theme that deals with the complexities that arise in the consumption of digital music (see for instance Asvanund et al., 2004; Plouffe, 2008; Song et al., 2009).

Next, a theme with average centrality and density sits in the origin of the map, showing a more defined theme around information-technology its usage and acceptance. These are associated to its perceived usefulness and the ability of organizations to create customer value. Research within this theme orbit around digital music services (as in $\mathrm{Chu} \& \mathrm{Lu}$, 2007; Kwong \& Park, 2008).

Third, a high-density and low centrality theme emerges in the upper-left quadrant. Terms included in this cluster are related to consumer behavior and its determinants, including attitudes, ethics, trust or perceived risk. Papers related to this cluster deal with the consumption of music in a digital environment (Cowart et al., 2008; Tepper \& Hargittai, 2009) and specifically with piracy as an alternative to purchase recorded music and the ethical implications it raises (e.g. Ingram \& Hinduja, 2008; Coyle et al., 2009; Harris \& Dumas, 2009).

Fourth, a peripheral theme, the one with the lowest centrality but comprised of terms that are densely connected, lies on the boundary of the upper-left quadrant. This cluster unambiguously connects MCR with strategic management by stressing internet-based, innovation in the industry (Song et al., 2009). Here diversity, creativity or knowledge, to 
mention some, are pinpointed as determinants of a firm's value creation and performance from a resource-based view of competitive advantage in industries with complex products such as the recording industry. ${ }^{5}$. Examples that are embedded within this theme discuss the local/global nature of the value chains in the music industry and its impact on music sales, hence on commercial success (Power \& Hallencreutz, 2007), project-based performance in the live industry (Sedita, 2008) or industry-driven changes in the music market (Huygens et al., 2001; Mol et al., 2005).

Fifth, only one theme is found in the lower-left quadrant, i.e. low centrality and low density. It is related to music consumption and how it helps to define the self and to affirm identity, which stresses consumers' similarit(ies) and uniqueness and individual-differences (Shankar et al., 2009). This theme is linked to the research on music consumption that shares methodology with the ethnographical and sociological literature (Berger \& Heath, 2007). Note that by looking at next period's themes, this cluster can be classified as an emerging one.

Finally, two transversal themes emerge in the lower-right quadrant (high centrality and low density), both related to music and piracy. The one with the lowest density draws on law and economics to undertake an economic analysis of intellectual property (Varian, 2005). A common term is the unauthorized use of information goods, specifically its implications, including the welfare analysis of music sharing, an approach that draws on theoretical models in order to identify expected changes in profits and consumer surplus (Peitz \& Waelbroeck, 2006a). As a result, infringement is shown to be highly dependent on demand and market assumptions, such as the possibility of indirect appropriability, the existence of network externalities, or the effective copyright protection, which may depend on national culture (Dejean, 2009; Oberholzer-Gee \& Strumpf, 2007).

Then, the theme with the highest centrality and density slightly below the origin is also related to information goods from a managerial and marketing perspectives. Software piracy emerges as the initial approach under which to analyze the impact of digitization and online (peer-to-peer) sharing of music, as well as strategies and responses to the threat it poses to the industry (Bhattacharjee et al., 2006a). In close relation we find digital music and the evolution of recorded music sales and profitability of the industry (Bhattacharjee

\footnotetext{
${ }^{5}$ While the theme in this cluster looks at the supply side, note that all works reviewed discuss the implications the organization of the industry has on consumers and the consumption of music.
} 
et al., 2007). Terms such as market power or integration, price dispersion and the costs of reproducing digital goods stress the specifics of the industry and how they affect the demand side which is represented by terms such as consumer ethics and intention and antecedents to behavior (Shang et al., 2008).

\subsubsection{Period 2010-2020}

Figure 6 shows the thematic map from 2010 on. First, one motor theme is identified (the one with the highest centrality and density) that defines a research line around online music. It relates with the consumption and construction of online contents and information by consumers (Oestreicher-Singer \& Zalmanson, 2013). Particularly, social networking platforms, such as Facebook, allows the music consumer to define its true self, and use experience and emotions in a process where consumption turns into prosumption (Belk, 2013). Borrowed from the sociology of culture, this theme also incorporates considerations on distinction and omnivore cultural consumption (Atkinson, 2011).

Second, a cluster with low centrality but larger than average density (upper-left quadrant) includes the central terms knowledge, networks and variety, along with less central ones creativity, labor-market, variety or ecology. This theme revolves around the new possibilities of knowledge and information sharing for the co-creation of value (Hauge \& Hracs, 2010; Galbreth et al., 2012; Gamble \& Gilmore, 2013).

Third, a rather small and isolated theme (the one with lowest centrality) includes terms related to the live industry — music festivals, event, performance quality or destination loyalty - along with consumer-related ones — attendees' antecedents behavioural intentions (as in Tanford \& Jung, 2017). Interestingly, while live music is gaining momentum as a means of music consumption, the topic of research appears to be marginal and disconnected from the mainstream of the research field.

In the boundary of the upper-left quadrant we find a cluster with an average density but low centrality. This theme follows a sociology perspective for the analysis of the music industry and the popular music consumer including terms such as culture and subcultures or brand communities that address the expressive nature of symbolic consumption (Goulding et al., 2013; Weijo et al., 2014; Hietanen \& Rokka, 2015).

Next, a theme sits in the margin of the fourth quadrant (average centrality and low 
density). Central terms are sales dynamics and model, word-of-mouth, reviews and behaviour, which stresses the mediated nature of cultural consumption and the role that digital media play in driving revenue (Garg et al., 2011; Dewan \& Ramaprasad, 2012, 2014; Chen et al., 2015).

The lower-right quadrant includes three clusters; these are high-centrality (well-integrated within the field) and low-density (not fully developed) themes. First, a theme on intellectual property and copyright keeps the transversality of the one found in the first period. It looks at the impact on the industry and welfare implications of technological change. It also deals with how technologies have had a decisive impact on the music industry and makes it necessary to redesign the legal bases of the music market, in order to follow the technological-change updates. While it borrows from the previous literature on piracy, this theme widens the scope of topics included (Adermon \& Liang, 2014; Galbreth et al., 2012; Moreau, 2013). Next, a theme which stresses the service dominant logic of marketing in relation to consumer and users, identity, participation and innovation (Ordanini et al., 2011; Chaney, 2012). Finally, the theme with the lowest density draws on piracy, services quality and customer loyalty. This theme illustrates the necessity to find strategies fit for the new uses of information-technology by market participants in the attempt to benefit from media's potential to create brand engagement and commitment (Calder et al., 2016; Oestreicher-Singer \& Zalmanson, 2013).

\section{Directions for future research}

This review yields insight into the diversity of the intellectual roots from which MCR has been undertaken and its expansion and the evolution of the themes that shape the research agenda, and the connections between them. In this regard, bibliographic coupling and conceptual mapping have proven useful tools to identify the research front and the topics of analysis within the field as well as their evolution. However, these have also highlighted gaps in the research agenda suggesting potential areas for future work. Next, we discuss these. 


\subsection{Future directions - context}

Understanding music consumption entails analyzing the context in which it takes place. The nature of music contents and the industries that supply it (recorded and live) have been identified and incorporated into the research field. Yet, as the conceptual mapping of the field shows, while digital and online music consumption have been central to MCR, live music is at best a marginal theme lacking integration with the core of the literature. This is particularly surprising as live music has become the most relevant source of income for musicians worldwide. ${ }^{6}$

Some influential papers have underscored the connection of media-based consumption with the demand for live performances (Mortimer et al., 2012; Nguyen et al., 2014; Papies \& van Heerde, 2017). Still, an in-depth analysis should acknowledge that the demand for live music exceeds the demand for music itself, something which calls for a broader scope in the analysis to include unexplored issues regarding live music consumer behavior, such as customer experience, immersion or loyalty in live performances. In this regard, research lacks a coherent look into the mapping of the symbolic nature of live music consumption and its collective character into the drives and constraints that operate at the individuals' level and how these define the demand for live shows. In short, compared to media-based consumption, self-expression becomes a stronger motivation of live music participation, which allows to a more detailed and differential look at the consumer's tastes and preferences and how they shape demand.

Furthermore, while the relation between consumers and technology has been considered as the domain of recorded music, it can also shed light on live consumption. In this regard research could benefit from incorporating technology adoption, value co-creation through online networks participation and user-generated content, or the role of discovery and innovativeness in the analysis of live consumption. Put differently, live music research could both exploit and expand the catalog of methodological categories currently used in $\mathrm{MCR}^{7}$

\footnotetext{
${ }^{6}$ See for instance "The Economics of Glastonbury", at https://www.economist.com/the-economistexplains/2014/06/24/the-economics-of-glastonbury. Article retrieved on August 23rd 2020.

${ }^{7}$ The streaming of live events provides a good illustration. It has been around for a while but only lately (and due to the COVID-19 shock) has it become the default option to consumers. Any analysis of this business model and its sustainability should take into account what is already known from streaming but also account for the particularities of live music consumption.
} 


\subsection{Future directions - theory}

Incorporating the determinants of consumer behavior and how these operate towards the formation of tastes and preferences remains a well-established strategy towards the theoretical identification of the antecedents and structural constraints —as opposed to the individual explanations - to music consumption. And while the reviewed literature provides a detailed account of the antecedents of consumption, the analysis of structural constraints has been less central to the field. Note that, given the experiential and mediated nature of music consumption, consumers form their preferences (and hence their demand) through learning-by-consuming, social influence, or, most significantly, through the influence of specific market actors.

In cultural markets, consumers face information asymmetries, an abundant supply of content and a lack of knowledge of the actual choice set. As a result, a variety of reputed actors or intermediaries emerge. These affect what is consumed through gatekeeping, tastemaking, selection and signaling of supply and legitimization of cultural practices. While there is some fragmented research on music consumption as a mediated form of cultural consumption, the reviewed literature focuses on gatekeeping effects on innovations, lacking a systematic view of the market mechanisms that cultural mediation trigger and how they affect consumption from an economic and business standpoint. Specifically, looking at a dynamic area such as the service-dominant logic, mediated consumption imposes structural constraints to the ability of consumers to participate in value co-creation.

In this regard, two aspects stand out as worthy of interest. On the one hand, the static analysis of cultural mediation and the resources (economic or symbolic) invested in cultural markets that foster the connection of content suppliers with audiences. This entails identifying what strategies are implemented and how effective these are in shaping music consumption. On the other hand, research has to account for the dynamics of cultural mediation. The dynamic and disruptive nature of cultural practices is changing the balance and clout of the different intermediaries. As consumers embrace new ways of consuming music, the roles of existing intermediaries change as new ones may emerge. It is important to note that mediation is less of an issue when highly concentrated, as with recorded music prior to the expansion of file-sharing. However, as more actors mediate consumption and the degree of complexity increases research should take a close look at 
what value intermediaries add to consumers. In this respect, new actors such as reputed festivals, streaming services, online platforms' recommendation systems, or user-generated content through social networking provide a handful of examples of the increasing diversity and complexity of the topic.

Furthermore, this abundance of actors and the new role consumers play in the field could reflect a trend towards the disintermediation of cultural consumption and/or the emergence of new decentralized players and prescribers who may influence what (and how) music contents are consumed. On this matter, while some papers in the marketing literature on value co-creation or word-of-mouth are tangentially related to this topic they disregard the big picture of mediated cultural consumption.

Besides mediated consumption, gender provides another example of structural constraints at play that could be further explored. There are very few articles that include a gender perspective in MCR, and they do it from a sociology and/or ethnographic standpoint (Meyers-Levy \& Zhu, 2010; Donze, 2017). Scholarly research in cultural consumption has for a long time consistently identified evidence of different participation rates across genders, the so-called gender effect, which leaves plenty of scope to research into the structural constraints individuals face. Studies in MCR could take into account gender in connection to other dimensions involved in music participation: the role of gender in technological adoption, value co-creation and social network participation, self-expression, the mediation and disintermediation of consumption or the different patterns of music use and choices on genres and styles are examples of research lines not yet fully exploited. Why these arise and how they translate into participation could provide additional and deeper understanding of the consumption of music.

\subsection{Future directions - methodology}

The use of quantitative methods in MCR is widespread, as many of the most influential works, the research front and the topics reviewed show. Using evidence to support theoretical claims is thus standard practice. The digitization of music has brought not only new practices but also a huge digital footprint which could provide information "about aspects of human behaviour which have previously been difficult to observe" (Taylor et al., 2014). 
The use of non-traditional information sources enhances the range of socio-economic data scholars apply to broaden the understanding of consumer behavior and motivations and the different roles consumers adopt online. Next, the use of non-standard data sources across the different themes emerging from figure 6 is proposed. First, the use of social networking and social interactions data to identify opinions and sentiments on different market actors are of direct use in topics related to brand communities and subcultures, identity, word-of-mouth or loyalty. Second, incorporating quantifiable audio features from tracks to model, identify and segment music consumers can help the empirical development of consumer behavior, behavioral intentions and innovation ${ }^{8}$. Third, gathering targeted information through web scraping from online reviews, blogging sites or crowdfunding platforms to assess user involvement in value and content creation. Fourth, the use of web or other platform-specific search indices as metrics of consumers' awareness to identify consumers' search strategies driving supply discovery and/or reducing information-related costs helping understand the dynamics of taste formation and, hence, consumption (as suggested in Montoro-Pons \& Cuadrado-García, 2020).

Summarizing, online technologies make a vast amount of information (both objective and subjective) available to researchers, which can be exploited to gain insights into the market.

\section{Conclusions}

As a distinguishable field of study, music consumption has gained momentum in the last twenty years. From 2000 to 2020 the scientific output grew at an annual growth rate of over $5 \%$, and the number of published articles in the field has experienced a (more than) tenfold increase. The foregoing review offers a novel approach to understanding MCR, a field of research overlapping consumption behavior, ethics, innovations and technology adoption and sustainable consumption practices. Furthermore, it has the value of being the first systematic appraisal of the extant literature.

The selection of documents has been quantitatively analyzed using bibliometric techniques in combination with an in-depth assessment and interpretation of the results pro-

\footnotetext{
${ }^{8}$ Some streaming services allow to extract songs' audio features using their Web API through library application programming interface.
} 
ducing a detailed insight into the intellectual structure of the field, its background (through co-citation analysis) and its research front and evolution (through bibliographic coupling). It has shown that, in terms of scientific output and impact, the most successful methodological avenues draw on economics (especially the dynamic analysis of market institutions and their impact on consumer behavior), marketing (the experiential nature of music consumption and its role in redefining the creation of value through new cultural institutions such as social networking and digital devices) and the mixture of both.

Moreover, thematic mapping makes explicit the conceptual structure of MCR by classifying high-impact research themes and their potential. Based on it, a sustained scholarly interest on copyright, a transversal theme, and its relation to consumer behavior has been identified, which has evolved as consumers move from being (nonlegal) users of protected content to subscribers of online platforms. From an institutional standpoint these changes take place in a mediated consumption model where the adoption of new technological developments disrupts the role of market intermediaries. Furthermore, the evolution of the research on the identity of online consumers, from an emerging to a motor theme, highlights new avenues of analysis in the field.

This study has some limitations related to the undertaken approach. First, the database of choice and the documents it excludes (books or book chapters that are important in certain disciplines) might limit the results. However, it should be noted that the use of articles in (WoS/Scopus) indexed journals is the usual practice not only in bibliometrics but in systematic reviews in general. Second, quantitative techniques that allow the analysis of large amount of bibliographic data, when used in isolation, also imply losing detailed information (van Eck \& Waltman, 2014). To overcome this, expert and detailed assessment of the output has been used and meaningful results support the adequacy and usefulness of the undertaken approach. Finally, the use of keywords in the conceptual mapping of the field excludes relevant information contained in other fields of the document such as the title or abstract. Yet, there is a trade-off in the insight such fine-grained information sources provide and the ability to derive general results. 


\section{References}

Adermon, A. \& Liang, C.-Y. (2014). Piracy and music sales: The effects of an anti-piracy law. Journal of Economic Behavior 85 Organization, 105, 90-106.

Adomavicius, G., Bockstedt, J., \& Curley, S. P. (2015). Bundling effects on variety seeking for digital information goods. Journal of Management Information Systems, 31(4), 182-212.

Aguiar, L. (2017). Let the music play? Free streaming and its effects on digital music consumption. Information Economics and Policy, 41, 1-14.

Aguiar, L. \& Waldfogel, J. (2018). As streaming reaches flood stage, does it stimulate or depress music sales? International Journal of Industrial Organization, 57, 278-307.

Aguillo, I. F. (2012). Is Google Scholar useful for bibliometrics? A webometric analysis. Scientometrics, 91(2), 343-351.

Ahuvia, A. C. (2005). Beyond the extended self: Loved objects and consumers' identity narratives. Journal of Consumer Research, 32(1), 171-184.

Akar, E. \& Topçu, B. (2011). An examination of the factors influencing consumers' attitudes toward social media marketing. Journal of Internet Commerce, 10(1), 35-67.

Anderson, J. C. \& Gerbing, D. W. (1988). Structural equation modeling in practice: A review and recommended two-step approach. Psychological Bulletin, 103(3), 411.

Aria, M. \& Cuccurullo, C. (2017). bibliometrix: An R-tool for comprehensive science mapping analysis. Journal of Informetrics, 11(4), 959-975.

Aria, M., Misuraca, M., \& Spano, M. (2020). Mapping the evolution of social research and data science on 30 years of social indicators research. Social Indicators Research, (pp. 1-29).

Arli, D. \& Tjiptono, F. (2016). Consumer digital piracy behaviour among youths: Insights from Indonesia. Asia Pacific Journal of Marketing and Logistics, 28(5), 898-922.

Arli, D., Tjiptono, F., \& Porto, R. (2015). The impact of moral equity, relativism and attitude on individuals' digital piracy behaviour in a developing country. Marketing Intelligence \& Planning, $33(3), 348-365$.

Assassi, I. (2007). The programming strategies and relationships of theatres: An analysis based on the French experience. International Journal of Arts Management, (pp. 50-64). 
Asvanund, A., Clay, K., Krishnan, R., \& Smith, M. (2004). An empirical analysis of network externalities in peer-to-peer music-sharing networks. Inforation Systems Research, 15(2), 155174.

Atkinson, W. (2011). The context and genesis of musical tastes: Omnivorousness debunked, Bourdieu buttressed. Poetics, 39(3), 169-186.

Bakos, J. Y. (1997). Reducing buyer search costs: Implications for electronic marketplaces. Management Science, 43(12), 1676-1692.

Bakos, Y., Brynjolfsson, E., \& Lichtman, D. (1999). Shared information goods. The Journal of Law and Economics, 42(1), 117-156.

Banks, J. \& Deuze, M. (2009). Co-creative labour. International Journal of Cultural Studies, 12(5), 419-431.

Bar-Ilan, J., Levene, M., \& Lin, A. (2007). Some measures for comparing citation databases. Journal of Informetrics, 1(1), 26-34.

Barney, J. (1991). Firm resources and sustained competitive advantage. Journal of Management, 17(1), 99-120.

Baumgarth, C. (2009). Brand orientation of museums: Model and empirical results. International Journal of Arts Management, (pp. 30-45).

Baym, N. K. \& Burnett, R. (2009). Amateur experts: International fan labour in Swedish independent music. International Journal of Cultural Studies, 12(5), 433-449.

Beaven, Z. \& Laws, C. (2007). Never let me down again: Loyal customer attitudes towards ticket distribution channels for live music events: A netnographic exploration of the US leg of the Depeche Mode 2005-2006 world tour. Managing Leisure, 12(2-3), 120-142.

Belk, R. W. (1988). Possessions and the extended self. Journal of Consumer Research, 15(2), $139-168$

Belk, R. W. (2013). Extended self in a digital world. Journal of Consumer Research, 40(3), $477-500$.

Berger, J. \& Heath, C. (2007). Where consumers diverge from others: Identity signaling and product domains. Journal of Consumer Research, 34(2), 121-134.

Berlin, N., Bernard, A., \& Fuerst, G. (2015). Time spent on new songs: word-of-mouth and price effects on teenager consumption. Journal of Cultural Economics, 39(2), 205-218. 
Bhattacharjee, S., Gopal, R. D., Lertwachara, K., \& Marsden, J. R. (2006a). Consumer search and retailer strategies in the presence of online music sharing. Journal of Management Information Systems, 23(1), 129-159.

Bhattacharjee, S., Gopal, R. D., Lertwachara, K., \& Marsden, J. R. (2006b). Impact of legal threats on online music sharing activity: An analysis of music industry legal actions. Journal of Law \& Economics, 49(1), 91-114.

Bhattacharjee, S., Gopal, R. D., Lertwachara, K., Marsden, J. R., \& Telang, R. (2007). The effect of digital sharing technologies on music markets: A survival analysis of albums on ranking charts. Management Science, 53(9), 1359-1374.

Bhattacharjee, S., Gopal, R. D., \& Sanders, G. L. (2003). Digital music and online sharing: Software piracy 2.0? Communications of the ACM, 46(7), 107-111.

Bonner, S. \& O’Higgins, E. (2010). Music piracy: Ethical perspectives. Management Decision, 48(9), 1341-1354.

Boorsma, M. (2006). A strategic logic for arts marketing: Integrating customer value and artistic objectives. International Journal of Cultural Policy, 12(1), 73-92.

Borja, K. \& Dieringer, S. (2016). Streaming or stealing? The complementary features between music streaming and music piracy. Journal of Retailing and Consumer Services, 32, 86-95.

Bourdieu, P. (1984). Distinction: A social critique of the judgement of taste. Harvard University Press.

Bradshaw, A. (2010). Before method: Axiomatic review of arts marketing. International Journal of Culture, Tourism and Hospitality Research, 4(1), 8-19.

Brynjolfsson, E. \& Hitt, L. M. (2000). Beyond computation: Information technology, organizational transformation and business performance. Journal of Economic Perspectives, 14(4), 23-48.

Cahlik, T. (2000a). Comparison of the maps of science. Scientometrics, 49(3), 373-387.

Cahlik, T. (2000b). Search for fundamental articles in economics. Scientometrics, 49(3), 389-402.

Calder, B. J., Isaac, M. S., \& Malthouse, E. C. (2016). How to capture consumer experiences: A context-specific approach to measuring engagement predicting consumer behavior across qualitatively different experiences. Journal of Advertising Research, 56(1), 39-52.

Caldwell, M. (2001). Applying general living systems theory to learn consumers' sense making in attending performing arts. Psychology $\&$ Marketing, 18(5), 497-511. 
Callon, M., Courtial, J.-P., Turner, W. A., \& Bauin, S. (1983). From translations to problematic networks: An introduction to co-word analysis. Social Science Information, 22(2), 191-235.

Callon, M., Courtial, J.-P., \& Laville, F. (1991). Co-word analysis as a tool for describing the network of interactions between basic and technological research: The case of polymer chemistry. Scientometrics, 22(1), 155-205.

Camarero, C. \& Garrido, M. J. (2008). The influence of market and product orientation on museum performance. International Journal of Arts Management, (pp. 14-26).

Cameron, S. (2016). Past, present and future: Music economics at the crossroads. Journal of Cultural Economics, 40(1), 1-12.

Cameron, S. (2018). The economics of music. Elgar Research Reviews in Economics. Edward Elgar Publishing Limited.

Caves, R. E. (2000). Creative industries: Contracts between art and commerce. Number 20. Harvard University Press.

Chaney, D. (2012). The music industry in the digital age: Consumer participation in value creation. International Journal of Arts ManagementT, 15(1), 42-52.

Chen, H., De, P., \& Hu, Y. J. (2015). IT-enabled broadcasting in social media: An empirical study of artists' activities and music sales. Information Systems Research, 26(3), 513-531.

Chiang, E. P. \& Assane, D. (2007). Determinants of music copyright violations on the university campus. Journal of Cultural Economics, 31(3), 187-204.

Chiou, J., Huang, C., \& Lee, H. (2005). The antecedents of music piracy attitudes and intentions. Journal of Business Ethics, 57(2), 161-174.

Choi, H. \& Burnes, B. (2017). Bonding and spreading co-creative relationships and interaction with consumers in South Korea's indie music industry. Management Decision, 55(9), 1905-1923.

Chu, C.-W. \& Lu, H.-P. (2007). Factors influencing online music purchase intention in Taiwan An empirical study based on the value-intention framework. Internet Research, 17(2), 139-155.

Cluley, R. (2013). Downloading deviance: Symbolic interactionism and unauthorised file-sharing. Marketing Theory, 13(3), 263-274.

Cobo, M. J., López-Herrera, A. G., Herrera-Viedma, E., \& Herrera, F. (2011). An approach for detecting, quantifying, and visualizing the evolution of a research field: A practical application to the fuzzy sets theory field. Journal of Informetrics, 5(1), 146-166. 
Connolly, M. \& Krueger, A. B. (2006). Rockonomics: The economics of popular music. In V. Ginsburg \& D. Throsby (Eds.) Handbook of the Economics of Art and Culture, vol.1 (pp. 667719). Amsterdam: Elsevier North-Holland.

Courtial, J. P. (1989). Qualitative models, quantitative tools and network analysis. Scientometrics, $15(5-6), 527-534$.

Courtial, J. \& Callon, M. (1991). Indicators for the identification of strategic themes within a research programme. Scientometrics, 21(3), 447-457.

Cova, B., Kozinets, R. V., \& Shankar, A. (2007). Consumer tribes. Routledge.

Cowart, K. O., Fox, G. L., \& Wilson, A. E. (2008). A structural look at consumer innovativeness and self-congruence in new product purchases. Psychology $\&$ Marketing, 25(12), 1111-1130.

Cox, J. \& Collins, A. (2014). Sailing in the same ship? Differences in factors motivating piracy of music and movie content. Journal of Behavioral and Experimental Economics, 50, 70-76.

Coyle, J. R., Gould, S. J., Gupta, P., \& Gupta, R. (2009). "To buy or to pirate": The matrix of music consumers' acquisition-mode decision-making. Journal of Business Research, 62(10), 1031-1037.

Csardi, G. \& Nepusz, T. (2006). The igraph software package for complex network research. InterJournal, Complex Systems, 1695.

Dabić, M., Vlačić, B., Paul, J., Dana, L. P., Sahasranamam, S., \& Glinka, B. (2020). Immigrant entrepreneurship: A review and research agenda. Journal of Business Research, 113(March), $25-38$.

Daellenbach, K., Kusel, R., \& Rod, M. (2015). The ties that bind? Online musicians and their fans. Asia Pacific Journal of Marketing and Logistics, 27(2), 168-190.

Datta, H., Knox, G., \& Bronnenberg, B. J. (2018). Changing their tune: How consumers' adoption of online streaming affects music consumption and discovery. Marketing Science, 37(1), 5-21.

Davis, F. D. (1989). Perceived usefulness, perceived ease of use, and user acceptance of information technology. MIS Quarterly, (pp. 319-340).

de Winter, J. C., Zadpoor, A. A., \& Dodou, D. (2014). The expansion of Google Scholar versus Web of Science: A longitudinal study. Scientometrics, 98(2), 1547-1565.

DeFillippi, R. J. \& Arthur, M. B. (1998). Paradox in project-based enterprise: The case of film making. California Management Review, 40(2), 125-139. 
Dejean, S. (2009). What can we learn from empirical studies about piracy? Cesifo Economic Studies, 55(2), 326-352.

Dewan, S. \& Ramaprasad, J. (2012). Music blogging, online sampling, and the long tail. Information Systems Research, 23(3, 2), 1056-1067.

Dewan, S. \& Ramaprasad, J. (2014). Social media, traditional media and music sales. MIS Quaterly, 38(1), 101-121.

Dhar, V. \& Chang, E. A. (2009). Does chatter matter? The impact of user-generated content on music sales. Journal of Interactive Marketing, 23(4), 300-307.

Dierickx, I. \& Cool, K. (1989). Asset stock accumulation and sustainability of competitive advantage. Management Science, 35(12), 1504-1511.

Dilmperi, A., King, T., \& Dennis, C. (2017). Toward a framework for identifying attitudes and intentions to music acquisition from legal and illegal channels. Psychology 65 Marketing, 34(4), 428-447.

Donze, P. L. (2017). Gender and popular culture: A comparison of promoter and listener preferences for popular music artists. Sociological Perspectives, 60(2), 338-354.

Earl, P. (2001). Simon's travel theorem and the demand for live music. Journal of Economic Psychology, 22(3), 335-358.

Eck, N. J. v. \& Waltman, L. (2009). How to normalize cooccurrence data? an analysis of some well-known similarity measures. Journal of the American Society for Information Science and Technology, 60(8), 1635-1651.

Eisend, M. (2019). Explaining digital piracy: A meta-analysis. Information Systems Research, $30(2), 636-664$.

Ekinsmyth, C. (2002). Project organization, embeddedness and risk in magazine publishing. Regional Studies, 36(3), 229-243.

Elberse, A. (2010). Bye-bye bundles: The unbundling of music in digital channels. Journal of Marketing, 74(3), 107-123.

Emmons, S., Kobourov, S., Gallant, M., \& Börner, K. (2016). Analysis of network clustering algorithms and cluster quality metrics at scale. PloS one, 11(7), e0159161.

Fetscherin, M. (2009). Importance of cultural and risk aspect in music piracy: A cross-national comparison among university students . Journal of Electronic Commerce Research, 10(1), 42-55. 
Firat, A. F. \& Venkatesh, A. (1995). Liberatory postmodernism and the reenchantment of consumption. Journal of Consumer Research, 22(3), 239-267.

Fornell, C. \& Larcker, D. F. (1981). Evaluating structural equation models with unobservable variables and measurement error. Journal of Marketing Research, 18(1), 39-50.

Fox, M. (2004). E-commerce business models for the music industry. Popular Music and Society, $27(2), 201-220$.

Galbreth, M. R., Ghosh, B., \& Shor, M. (2012). Social sharing of information goods: Implications for pricing and profits. Marketing Science, 31(4), 603-620.

Gamble, J. \& Gilmore, A. (2013). A new era of consumer marketing? An application of cocreational marketing in the music industry. European Journal of Marketing, 47(11-12), 18591888.

Gamble, J. R., Brennan, M., \& McAdam, R. (2017). A rewarding experience? Exploring how crowdfunding is affecting music industry business models. Journal of Business Research, 70, 25-36.

Garfield, E. (1990a). Keywords plus-ISI's breakthrough retrieval method. Part 1. Expanding your searching power on Current Contents on Diskette. Current Contents, 32, 5-9.

Garfield, E. (1990b). Keywords plus takes you beyond title words. Part 2. Expanded journal coverage for Current Contents on Diskette, includes social and behavioral sciences. Current Contents, 33, 5-9.

Garfield, E. \& Sher, I. H. (1993). Key words plus[tm]-algorithmic derivative indexing. JournalAmerican Society for Information Science, 44, 298-298.

Garg, R., Smith, M. D., \& Telang, R. (2011). Measuring information diffusion in an online community. Journal of Management Information Systems, 28(2), 11-37.

Giddens, A. (1991). Modernity and self-identity: Self and society in the late modern age. Stanford University Press.

Giesler, M. (2006). Consumer gift systems. Journal of Consumer Research, 33(2), 283-290.

Giesler, M. (2008). Conflict and compromise: Drama in marketplace evolution. Journal of Consumer Research, 34(6), 739-753.

Gopal, R. D., Bhattacharjee, S., \& Sanders, G. L. (2006). Do artists benefit from online music sharing? The Journal of Business, 79(3), 1503-1533. 
Goulding, C., Shankar, A., \& Canniford, R. (2013). Learning to be tribal: Facilitating the formation of consumer tribes. European Journal of Marketing, 47(5-6), 813-832.

Goulding, C., Shankar, A., Elliott, R., \& Canniford, R. (2009). The marketplace management of illicit pleasure. Journal of Consumer Research, 35(5), 759-771.

Grabher, G. (2002). The project ecology of advertising: Tasks, talents and teams. Regional Studies, $36(3), 245-262$.

Granovetter, M. S. (1973). The strength of weak ties. American Journal of Sociology, 78(6), $1360-1380$.

Grönroos, C. (2008). Service logic revisited: Who creates value? And who co-creates? European Business Review, 20(4), 298-314.

Grönroos, C. (2011). Value co-creation in service logic: A critical analysis. Marketing Theory, 11(3), 279-301.

Guerzoni, M. \& Nuccio, M. (2014). Music consumption at the dawn of the music industry: The rise of a cultural fad. Journal of Cultural Economics, 38(2), 145-171.

Gundlach, G. T. \& Murphy, P. E. (1993). Ethical and legal foundations of relational marketing exchanges. Journal of Marketing, 57(4), 35-46.

Gupta, P., Chauhan, S., Paul, J., \& Jaiswal, M. P. (2020). Social entrepreneurship research: A review and future research agenda. Journal of Business Research, 113(April), 209-229.

Hampton-Sosa, W. (2019). The access model for music and the effect of modification, trial, and sharing usage rights on streaming adoption and piracy. Journal of Theoretical and Applied Electronic Commerce Research, 14(3), 126-155.

Handke, C., Balazs, B., \& Vallbe, J.-J. (2016). Going means trouble and staying makes it double: The value of licensing recorded music online. Journal of Cultural Economics, 40(3), 227-259.

Harris, L. C. \& Dumas, A. (2009). Online consumer misbehaviour: An application of neutralization theory. Marketing Theory, 9(4), 379-402.

Harzing, A. W. \& Alakangas, S. (2016). Google Scholar, Scopus and the Web of Science: A longitudinal and cross-disciplinary comparison. Scientometrics, 106(2), 787-804.

Hauge, A. \& Hracs, B. J. (2010). See the sound, hear the style: Collaborative linkages between indie musicians and fashion designers in local scenes. Industry and Innovation, 17(1), 113-129. 
Hesmondhalgh, D. (1996). Flexibility, post-fordism and the music industries. Media, Culture \& Society, 18(3), 469-488.

Hietanen, J. \& Rokka, J. (2015). Market practices in countercultural market emergence. European Journal of Marketing, 49(9-10), 1563-1588.

Hill, C. W. (2007). Digital piracy: Causes, consequences, and strategic responses. Asia Pacific Journal of Management, 24(1), 9-25.

Hirsch, P. (2000). Cultural industries revisited. Organization Science, 11(3), 356-361.

Hirschman, E. C. (1980). Innovativeness, novelty seeking, and consumer creativity. Journal of Consumer Research, 7(3), 283-295.

Holbrook, M., Lacher, K., \& LaTour, M. (2006). Audience judgments as the potential missing link between expert judgments and audience appeal: An illustration based on musical recordings of "My Funny Valentine". Journal of the Academy of Marketing Science, 34(1), 8-18.

Holbrook, M. B. \& Schindler, R. M. (1989). Some exploratory findings on the development of musical tastes. Journal of Consumer Research, 16(1), 119-124.

Hu, L.-t. \& Bentler, P. M. (1999). Cutoff criteria for fit indexes in covariance structure analysis: Conventional criteria versus new alternatives. Structural Equation Modeling: A Multidisciplinary Journal, 6(1), 1-55.

Huang, C. (2005). File sharing as a form of music consumption. International Journal of Electronic Commerce, 9(4), 37-55.

Hui, K.-L. \& Png, I. (2003). Piracy and the legitimate demand for recorded music. The BE Journal of Economic Analysis \& Policy, 2(1), 11.

Hulland, J. \& Houston, M. B. (2020). Why systematic review papers and meta-analyses matter: An introduction to the special issue on generalizations in marketing. Journal of the Academy of Marketing Science, 48(3), 351-359.

Huygens, M., Baden-Fuller, C., Van Den Bosch, F., \& Volberda, H. (2001). Co-evolution of firm capabilities and industry competition: Investigating the music industry, 1877-1997. Organization Studies, 22(6), 971-1011.

Ingram, J. R. \& Hinduja, S. (2008). Neutralizing music piracy: An empirical examination. Deviant Behavior, 29(4), 334-366.

Jain, S. (2008). Digital piracy: A competitive analysis. Marketing Science, 27(4), 610-626. 
Jarneving, B. (2007). Bibliographic coupling and its application to research-front and other core documents. Journal of Informetrics, 1(4), 287-307.

Johnson, W. R. (1985). The economics of copying. Journal of Political Economy, 93(1), 158-174.

Khouja, M. \& Park, S. (2007). Optimal pricing of digital experience goods under piracy. Journal of Management Information Systems, 24(3), 109-141.

Kim, J.-Y., Natter, M., \& Spann, M. (2009). Pay what you want: A new participative pricing mechanism. Journal of Marketing, 73(1), 44-58.

King, S. P. \& Lampe, R. (2003). Network externalities, price discrimination and profitable piracy. Information Economics and Policy, 15(3), 271-290.

Klein, C. C. \& Slonaker, S. W. (2010). Chart turnover and sales in the recorded music industry: 1990-2005. Review of Industrial Organization, 36(4), 351-372.

Koh, B., Hann, I.-H., \& Raghunathan, S. (2019). Digitization of music: Consumer adoption amidst piracy, unbundling and rebundling. MIS Quaterly, 43(1), 23+.

Kostoff, R. N. (1993). Co-word analysis. In B. Bozeman \& J. Melkers (Eds.), Evaluating RESD Impacts: Methods and Practice (pp. 63-78). Springer.

Krueger, A. B. (2005). The economics of real superstars: The market for rock concerts in the material world. Journal of Labor Economics, 23(1), 1-30.

Ku, R. S. R. (2002). The creative destruction of copyright: Napster and the new economics of digital technology. The University of Chicago Law Review, (pp. 263-324).

Kunze, O. \& Mai, L.-W. (2007). Consumer adoption of online music services. International Journal of Retail \&3 Distribution Management, 35(11), 862-877.

Kwong, S. W. \& Park, J. (2008). Digital music services: Consumer intention and adoption. Service Industries Journal, 28(10), 1463-1481.

Landes, W. M. \& Posner, R. A. (1989). An economic analysis of copyright law. The Journal of Legal Studies, 18(2), 325-363.

Levin, A. M., Dato-on, M. C., \& Rhee, K. (2004). Money for nothing and hits for free: The ethics of downloading music from peer-to-peer web sites. Journal of Marketing Theory and Practice, 12(1), 48-60. 
Lewis, G., Graham, G., \& Hardaker, G. (2005). Evaluating the impact of the internet on barriers to entry in the music industry. Supply Chain Management-An International Journal, 10(5), 349-356.

Liebowitz, S. J. (1985). Copying and indirect appropriability: Photocopying of journals. Journal of Political Economy, 93(5), 945-957.

Liebowitz, S. J. (2006). File sharing: Creative destruction or just plain destruction? Journal of Law and Economics, 49(1), 1-28.

Liebowitz, S. J. (2008). Testing file sharing's impact on music album sales in cities. Management Science, 54(4), 852-859.

Liebowitz, S. J. (2016). How much of the decline in sound recording sales is due to file-sharing? Journal of Cultural Economics, 40(1), 13-28.

Liebowitz, S. J. \& Margolis, S. E. (2009). Bundles of joy: The ubiquity and efficiency of bundles in new technology markets. Journal of Competition Law 83 Economics, 5(1), 1-47.

Liebowitz, S. J. \& Watt, R. (2006b). How to best ensure remuneration for creators in the market for music? Copyright and its alternatives. Journal of Economic Surveys, 20(4), 513-545.

Lim, W. M., Yap, S. F., \& Makkar, M. (2021). Home sharing in marketing and tourism at a tipping point: What do we know, how do we know, and where should we be heading? Journal of Business Research, 122(August 2020), 534-566.

Lopes, P. D. (1992). Innovation and diversity in the popular music industry, 1969 to 1990. American Sociological Review, 57(1), 56-71.

Lorenzen, M. \& Frederiksen, L. (2005). The management of projects and product experimentation: Examples from the music industry. European Management Review, 2(3), 198-211.

Lowry, P. B., Zhang, J., \& Wu, T. (2017). Nature or nurture? A meta-analysis of the factors that maximize the prediction of digital piracy by using social cognitive theory as a framework. Computers in Human Behavior, 68, 104-120.

Maffesoli, M. (1995). The time of the tribes: The decline of individualism in mass society. Sage.

Mahajan, V., Muller, E., \& Bass, F. M. (1990). New product diffusion models in marketing: A review and directions for research. Journal of Marketing, 54(1), 1-26.

March, J. G. (1991). Exploration and exploitation in organizational learning. Organization Science, $2(1), 71-87$. 
Mattsson, J. T., Peltoniemi, M., \& Parvinen, P. M. T. (2010). Genre-deviating artist entry: The role of authenticity and fuzziness. Management Decision, 48(9), 1355-1364.

McCourt, T. (2005). Collecting music in the digital realm. Popular Music and Society, 28(2), $249-252$.

Meyers-Levy, J. \& Zhu, R. J. (2010). Gender differences in the meanings consumers infer from music and other aesthetic stimuli. Journal of Consumer Psychology, 20(4), 495-507.

Mingers, J. \& Leydesdorff, L. (2015). A review of theory and practice in scientometrics. European Journal of Operational Research, 246(1), 1-19.

Miquel-Romero, M.-J. \& Montoro-Pons, J. D. (2017). Consumption habits, perception and positioning of content-access devices in recorded music. International Journal of Arts Management, 19(3), 4-18.

Moe, W. \& Fader, P. (2001). Modeling hedonic portfolio products: A joint segmentation analysis of music compact disc sales. Journal of Marketing Research, 38(3), 376-385.

Mol, J., Wijnberg, N., \& Carroll, C. (2005). Value chain envy: Explaining new entry and vertical integration in popular music. Journal of Management Studies, 42(2), 251-276.

Mol, J. M. \& Wijnberg, N. M. (2007). Competition, selection and rock and roll: The economics of payola and authenticity. Journal of Economic Issues, 41(3), 701-714.

Montoro-Pons, J. D. \& Cuadrado-García, M. (2008). Legal origin and intellectual property rights: An empirical study in the prerecorded music sector. European Journal of Law and Economics, $26(2), 153-173$.

Montoro-Pons, J. D. \& Cuadrado-García, M. (2011). Live and prerecorded popular music consumption. Journal of Cultural Economics, 35(1), 19-48.

Montoro-Pons, J. D. \& Cuadrado-García, M. (2020). Music festivals as mediators and their influence on consumer awareness. Poetics, 80, 101424.

Moreau, F. (2013). The disruptive nature of digitization: The case of the recorded music industry. International Journal of Arts Management, 15(2), 18-31.

Mortimer, J. H., Nosko, C., \& Sorensen, A. (2012). Supply responses to digital distribution: Recorded music and live performances. Information Economics and Policy, 24(1), 3-14.

Mu, J., Thomas, E., Qi, J., \& Tan, Y. (2018). Online group influence and digital product consumption. Journal of the Academy of Marketing Science, 46(5), 921-947. 
Muniz, A. M. \& O'guinn, T. C. (2001). Brand community. Journal of Consumer Research, 27(4), 412-432

Nelson, R. \& Winter, S. (1982). An evolutionary theory of economic change. Harvard University Press.

Nguyen, G. D., Dejean, S., \& Moreau, F. (2014). On the complementarity between online and offline music consumption: The case of free streaming. Journal of Cultural Economics, 38(4), 315-330.

Nokelainen, T. \& Dedehayir, O. (2015). Technological adoption and use after mass market displacement: The case of the LP record. Technovation, 36-37(February-March), 65-76.

Novos, I. E. \& Waldman, M. (1984). The effects of increased copyright protection: An analytic approach. Journal of Political Economy, 92(2), 236-246.

Oberholzer-Gee, F. \& Strumpf, K. (2007). The effect of file sharing on record sales: An empirical analysis. Journal of Political Economy, 115(1), 1-42.

Oestreicher-Singer, G. \& Zalmanson, L. (2013). Content or community? A digital business strategy for content providers in the social age. MIS Quaterly, 37(2), 591-616.

O’Hara, K. \& Brown, B. (2006). Consuming music together: Introduction and overview. In K. O'Hara \& B. Brown (Eds.), Consuming Music Together: Social and Collaborative Aspects of Music (pp. 3-17). Springer.

Ordanini, A., Miceli, L., Pizzetti, M., \& Parasuraman, A. (2011). Crowd-funding: Transforming customers into investors through innovative service platforms. Journal of Service Management, $22(4), 443-470$.

Ouellet, J.-F. (2007). The purchase versus illegal download of music by consumers: The influence of consumer response towards the artist and music. Canadian Journal of Administrative SciencesRevue Canadiense des Sciences de l'Administration, 24(2), 107-119.

Papies, D., Eggers, F., \& Wloemert, N. (2011). Music for free? How free ad-funded downloads affect consumer choice. Journal of the Academy of Marketing Science, 39(5), 777-794.

Papies, D. \& van Heerde, H. J. (2017). The dynamic interplay between recorded music and live concerts: The role of piracy, unbundling, and artist characteristics. Journal of Marketing, 81(4), 67-87. 
Paul, J. \& Benito, G. R. (2018). A review of research on outward foreign direct investment from emerging countries, including China: what do we know, how do we know and where should we be heading? Asia Pacific Business Review, 24(1), 90-115.

Paul, J. \& Criado, A. R. (2020). The art of writing literature review: What do we know and what do we need to know? International Business Review, 29(4), 101717.

Paul, J. \& Mas, E. (2019). Toward a 7-p framework for international marketing. Journal of Strategic Marketing, (pp. 1-21).

Peitz, M. \& Waelbroeck, P. (2006a). Piracy of digital products: A critical review of the theoretical literature. Information Economics and Policy, 18(4), 449-476.

Peitz, M. \& Waelbroeck, P. (2006b). Why the music industry may gain from free downloading The role of sampling. International Journal of Industrial Organization, 24(5), 907-913.

Peteraf, M. A. (1993). The cornerstones of competitive advantage: A resource-based view. Strategic Management Journal, 14(3), 179-191.

Peukert, C. (2019). The next wave of digital technological change and the cultural industries. Journal of Cultural Economics, 43(2), 189-210.

Plouffe, C. R. (2008). Examining "peer-to-peer" (P2P) systems as consumer-to-consumer (C2C) exchange. European Journal of Marketing, 42(11-12), 1179-1202.

Power, D. \& Hallencreutz, D. (2007). Competitiveness, local production systems and global commodity chains in the music industry: Entering the US market. Regional Studies, 41(3), 377-389.

Prahalad, C. K. \& Ramaswamy, V. (2004). Co-creation experiences: The next practice in value creation. Journal of Interactive Marketing, 18(3), 5-14.

R Core Team (2019). R: A language and environment for statistical computing. R Foundation for Statistical Computing, Vienna, Austria.

Rabinovich, E., Bailey, J., \& Carter, C. (2003). A transaction-efficiency analysis of an Internet retailing supply chain in the music CD industry. Decision Sciences, 34(1), 131-172.

Randhawa, K., Wilden, R., \& Hohberger, J. (2016). A bibliometric review of open innovation: Setting a research agenda. Journal of Product Innovation Management, 33(6), 750-772.

Reardon, J., McCorkle, D., Radon, A., \& Abraha, D. (2019). A global consumer decision model of intellectual property theft. Journal of Research in Interactive Marketing, 13(4), 509-528. 
Reavis-Conner, K. \& Rumelt, R. P. (1991). Software piracy: An analysis of protection strategies. Management Science, 37(2), 125-139.

Regner, T. \& Barria, J. A. (2009). Do consumers pay voluntarily? The case of online music. Journal of Economic Behavior \& Organization, 71(2), 395-406.

Rob, R. \& Waldfogel, J. (2006). Piracy on the high C's: Music downloading, sales displacement, and social welfare in a sample of college students. Journal of Law $\mathcal{E}$ Economics, 49(1), 29-62.

Rogers, E. M. (2003). Diffusion of innovations. New York: The Free Press.

Ruggeri, G., Orsi, L., \& Corsi, S. (2019). A bibliometric analysis of the scientific literature on fairtrade labelling. International Journal of Consumer Studies, 43(2), 134-152.

Saragih, H. (2019). Co-creation experiences in the music business: A systematic literature review. Journal of Management Development, 38(6), 464-483.

Schau, H. J., Muñiz Jr, A. M., \& Arnould, E. J. (2009). How brand community practices create value. Journal of Marketing, 73(5), 30-51.

Scherer, F. M. (2006). The Evolution of Music Markets. In V. Ginsburg \& D. Throsby (Eds.) Handbook of the Economics of Art and Culture, vol.1 (pp. 123-143). Amsterdam: Elsevier NorthHolland.

Schindler, R. M. \& Holbrook, M. B. (2003). Nostalgia for early experience as a determinant of consumer preferences. Psychology 83 Marketing, 20(4), 275-302.

Schouten, J. W. \& McAlexander, J. H. (1995). Subcultures of consumption: An ethnography of the new bikers. Journal of Consumer Research, 22(1), 43-61.

Scott, A. J. (2000). The cultural economy of cities: Essays on the geography of image-producing industries. London: Sage.

Sedita, S. R. (2008). Interpersonal and inter-organizational networks in the performing arts: The case of project-based organizations in the live music industry. Industry and Innovation, 15(5), 493-511.

Shang, R.-A., Chen, Y.-C., \& Chen, P.-C. (2008). Ethical decisions about sharing music files in the P2P environment. Journal of Business Ethics, 80(2), 349-365.

Shankar, A., Elliott, R., \& Fitchett, J. A. (2009). Identity, consumption and narratives of socialization. Marketing Theory, 9(1), 75-94. 
Shapiro, C. \& Varian, H. (1999). Information rules: A strategic guide to the network economy. Boston: Harvard Business School Press.

Sinclair, G. \& Green, T. (2016). Download or stream? Steal or buy? Developing a typology of today's music consumer. Journal of Consumer Behavior, 15(1), 3-14.

Sinclair, G. \& Saren, M. (2019). Guest editorial: Marketing and music in an age of digital reproduction. European Journal of Marketing, 53(3), 402-411.

Sinha, R. K., Machado, F. S., \& Sellman, C. (2010). Don’t think twice, it's all right: Music piracy and pricing in a DRM-free environment. Journal of Marketing, 74(2), 40-54.

Small, H. (1973). Co-citation in the scientific literature: A new measure of the relationship between two documents. Journal of the American Society for Information Science, 24(4), 265-269.

Small, H. (2004). On the shoulders of Robert Merton: Towards a normative theory of citation. Scientometrics, 60(1), 71-79.

Song, M., Parry, M. E., \& Kawakami, T. (2009). Incorporating network externalities into the technology acceptance model. Journal of Product Innovation Management, 26(3), 291-307.

Spulber, D. F. (1996). Market microstructure and intermediation. Journal of Economic Perspectives, 10(3), 135-152.

Steininger, D. M. \& Gatzemeier, S. (2019). Digitally forecasting new music product success via active crowdsourcing. Technological Forecasting and Social Change, 146, 167-180.

Stevans, L. K. \& Sessions, D. N. (2005). An empirical investigation into the effect of music downloading on the consumer expenditure of recorded music: A time series approach. Journal of Consumer Policy, 28(3), 311-324.

Styvén, M. E. (2010). The need to touch: Exploring the link between music involvement and tangibility preference. Journal of Business Research, 63(9-10), 1088-1094.

Šubelj, L., Van Eck, N. J., \& Waltman, L. (2016). Clustering scientific publications based on citation relations: A systematic comparison of different methods. PLoS ONE, 11(4), 1-23.

Takeyama, L. N. (1994). The welfare implications of unauthorized reproduction of intellectual property in the presence of demand network externalities. The Journal of Industrial Economics, (pp. 155-166).

Tanford, S. \& Jung, S. (2017). Festival attributes and perceptions: A meta-analysis of relationships with satisfaction and loyalty. Tourism Management, 61, 209-220. 
Tang, P. (2005). Digital copyright and the "new" controversy: Is the law moulding technology and innovation? Research Policy, 34(6), 852-871.

Taylor, L., Schroeder, R., \& Meyer, E. (2014). Emerging practices and perspectives on Big Data analysis in economics: Bigger and better or more of the same? Big Data and Society, 1(2), $1-10$.

Taylor, S. L. (2004). Music piracy-differences in the ethical perceptions of business majors and music business majors. Journal of Education for Business, 79(5), 306-310.

Teece, D. J., Pisano, G., \& Shuen, A. (1997). Dynamic capabilities and strategic management. Strategic Management Journal, 18(7), 509-533.

Tepper, S. J. \& Hargittai, E. (2009). Pathways to music exploration in a digital age. Poetics, $37(3), 227-249$.

Thompson, P., Jones, M., \& Warhurst, C. (2007). From conception to consumption: Creativity and the missing managerial link. Journal of Organizational Behavior, 28(5), 625-640.

Traag, V. A., Waltman, L., \& van Eck, N. J. (2019). From louvain to Leiden: Guaranteeing well-connected communities. Scientific Reports, 9(1), 1-12.

Tschmuck, P. (2003). How creative are the creative industries? A case of the music industry. Journal of Arts Management Law and Society, 33(2), 127-141.

Tu, Y. \& Lu, M. (2006). An experimental and analytical study of on-line digital music sampling strategies. International Journal of Electronic Commerce, 10(3), 39-70.

van Eck, N. J. \& Waltman, L. (2014). Visualizing Bibliometric Networks. In Y. Ding, R. Rousseau \& D. Wolfram (Eds.) Measuring Scholarly Impact. Methods and Practice (pp. 285-320). Cham: Springer International Publishing.

Vargo, S. L. \& Lusch, R. F. (2004). Evolving to a new dominant logic for marketing. Journal of Marketing, 68(1), 1-17.

Vargo, S. L. \& Lusch, R. F. (2008). Service-dominant logic: Continuing the evolution. Journal of the Academy of Marketing Science, 36(1), 1-10.

Varian, H. (2005). Copying and copyright. Journal of Economic Perspectives, 19(2), 121-138.

Varian, H. R. (2000). Buying, sharing and renting information goods. The Journal of Industrial Economics, 48(4), 473-488. 
Venkatesh, V., Morris, M. G., Davis, G. B., \& Davis, F. D. (2003). User acceptance of information technology: Toward a unified view. MIS Quarterly, (pp. 425-478).

Vogel, H. (1998). Entertainment industry economics. Cambridge: Cambridge University Press.

Waldfogel, J. (2014). Digitization, copyright, and the flow of new music products, In V. Ginsburg \& D. Throsby (Eds.) Handbook of the Economics of Art and Culture, vol.2 (pp. 277-297). Amsterdam: Elsevier North-Holland.

Waldfogel, J. (2017). How digitization has created a golden age of music, movies, books, and television. Journal of Economic Perspectives, 31(3), 195-214.

Waltman, L. \& Van Eck, N. J. (2013). A smart local moving algorithm for large-scale modularitybased community detection. The European Physical Journal B, 86(11), 471.

Wang, C.-c., Chen, C.-t., Yang, S.-c., \& Farn, C.-k. (2009). Pirate or buy? The moderating effect of idolatry. Journal of Business Ethics, 90(1), 81-93.

Wang, J., Yang, Z., \& Bhattacharjee, S. (2011). Same coin, different sides: Differential impact of social learning on two facets of music piracy. Journal of Management Information Systems, $28(3), 343-384$.

Weijo, H., Hietanen, J., \& Mattila, P. (2014). New insights into online consumption communities and netnography. Journal of Business Research, 67(10), 2072-2078.

Wenger, E. (2000). Communities of practice and social learning systems. Organization, 7(2), 225-246.

Wernerfelt, B. (1984). A resource-based view of the firm. Strategic Management Journal, 5(2), 171-180.

Williamson, O. E. (1975). Markets and hierarchies, volume 2630. New York: Free Press.

Williamson, O. E. (1985). The economic institutions of capitalism. New York: Free Press.

Wloemert, N. \& Papies, D. (2016). On-demand streaming services and music industry revenuesInsights from Spotify's market entry. International Journal of Research in Marketing, 33(2), 314-327.

Wood, E. H. \& Kinnunen, M. (2020). Emotion, memory and re-collective value: Shared festival experiences. International Journal of Contemporary Hospitality Management, 32(3), 1275-1298.

Zentner, A. (2006). Measuring the effect of file sharing on music purchases. Journal of Law \&6 Economics, 49(1), 63-90. 
Zhang, J. J., Fang, X., \& Sheng, O. R. L. (2006). Online consumer search depth: Theories and new findings. Journal of Management Information Systems, 23(3), 71-95. 
Table 1: Concepts included in the search.

\begin{tabular}{ll} 
& WoS search terms \\
\hline & Music consumption \\
& Music consumer \\
Consumption related & Music demand \\
& Music participation \\
& Music attendance \\
\hline \multirow{5}{*}{ Sales and revenue } & Music revenue \\
& Music sales \\
& Music purchase \\
\hline \multirow{5}{*}{ Market \& industry related } & Prerecorded music \\
& Live music \\
& Phonographic industry \\
& Music business \\
\hline
\end{tabular}

Table 2: Dataset: descriptive statistics.

\begin{tabular}{lrlr}
\hline Basic information & & Authorship & \\
Timespan & $2000: 2020$ & Authors & 801 \\
Sources (Journals) & 141 & Co-authors per documents & 2.24 \\
Documents & 455 & Collaboration index & 2.03 \\
Citations & 9985 & Single-authored documents & 106 \\
Average citations per documents & 21.95 & & \\
\hline Document contents & & & 940 \\
Keywords & 1330 & Keywords Plus & \\
References & 16981 & & \\
\hline \hline
\end{tabular}

Table 3: Cross-country scientific production and scientific impact: top ten countries.

\begin{tabular}{lrrlrr}
\hline Country's output & $\mathbf{N}$ & $\mathbf{\%}$ & Country's impact & TC & AAC \\
\hline USA & 153 & 0.3385 & USA & 4801 & 31.38 \\
United Kingdom & 50 & 0.1106 & United Kingdom & 984 & 19.68 \\
France & 34 & 0.0752 & Canada & 859 & 47.72 \\
Germany & 30 & 0.0664 & Germany & 594 & 19.80 \\
Australia & 24 & 0.0531 & China & 488 & 32.53 \\
Canada & 18 & 0.0398 & Italy & 469 & 31.27 \\
Spain & 18 & 0.0398 & Netherlands & 272 & 16.00 \\
Netherlands & 17 & 0.0376 & France & 270 & 7.94 \\
China & 15 & 0.0332 & Australia & 182 & 7.58 \\
Italy & 15 & 0.0332 & Israel & 155 & 51.67 \\
\hline N: number of documents; \%: relative frequency; TC: total citations; AAC: average article citations.
\end{tabular}


Table 4: Most relevant sources

\begin{tabular}{llr}
\hline Rank & Sources & Articles \\
\hline 1 & Information Economics and Policy & 28 \\
2 & Journal of Cultural Economics & 27 \\
3 & European Journal of Marketing & 15 \\
4 & Consumption Markets\& Culture & 14 \\
& Journal of Business Research & 14 \\
& Journal of Management Information Systems & 14 \\
5 & International Journal of Arts Management & 13 \\
& Journal of Business Ethics & 13 \\
6 & Marketing Theory & 10 \\
7 & Management Science & 9 \\
& Psychology \& Marketing & 9 \\
8 & Journal of Consumer Behaviour & 8 \\
& Technological Forecasting and Social Change & 8 \\
9 & International Journal of Research in Marketing & 7 \\
& Journal of Consumer Research & 7 \\
& Journal of Media Economics & 7 \\
\multirow{2}{*}{10} & Management Decision & 7 \\
& Electronic Commerce Research and Applications & 6 \\
& Information Systems Research & 6 \\
& Marketing Science & 6 \\
\hline
\end{tabular}




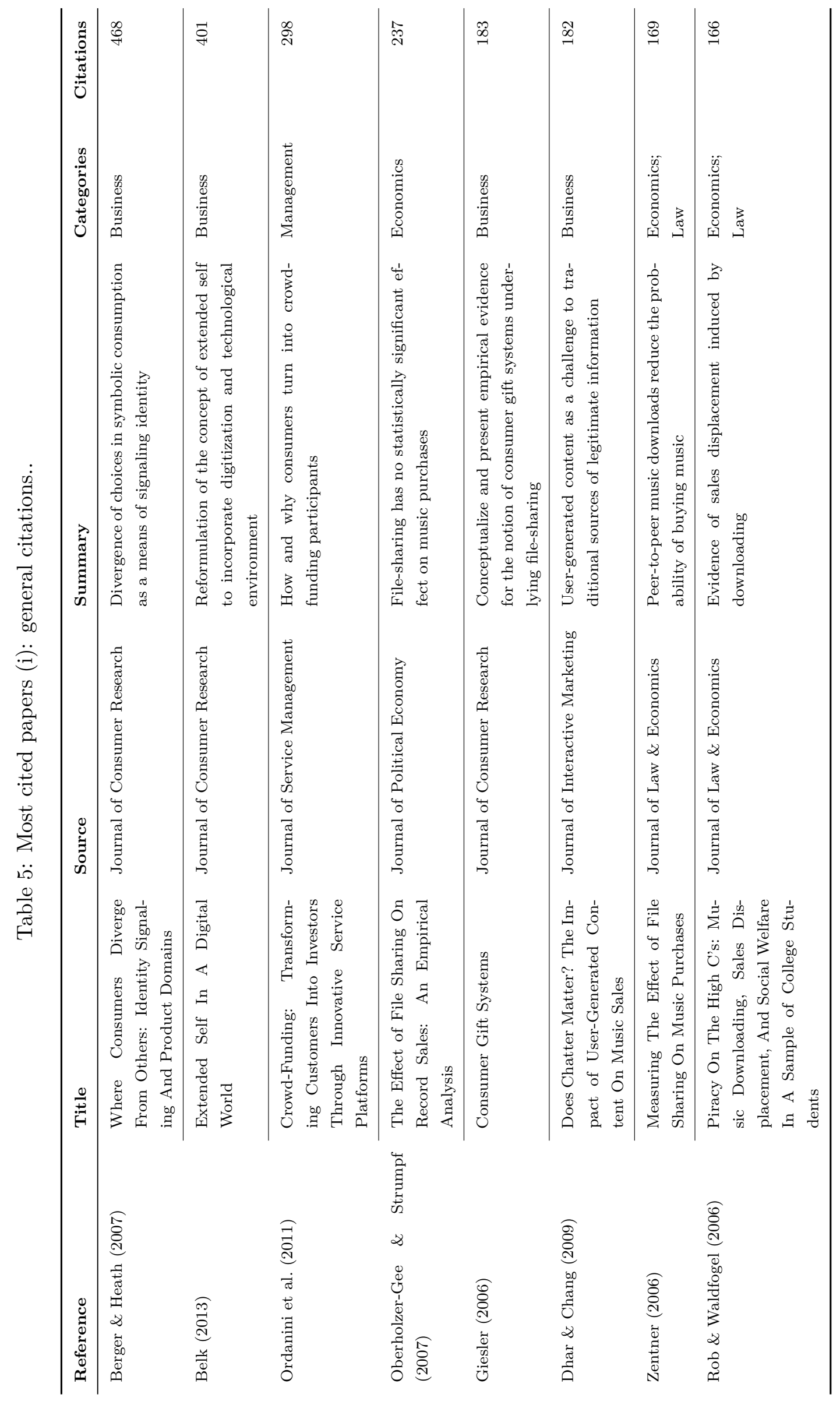




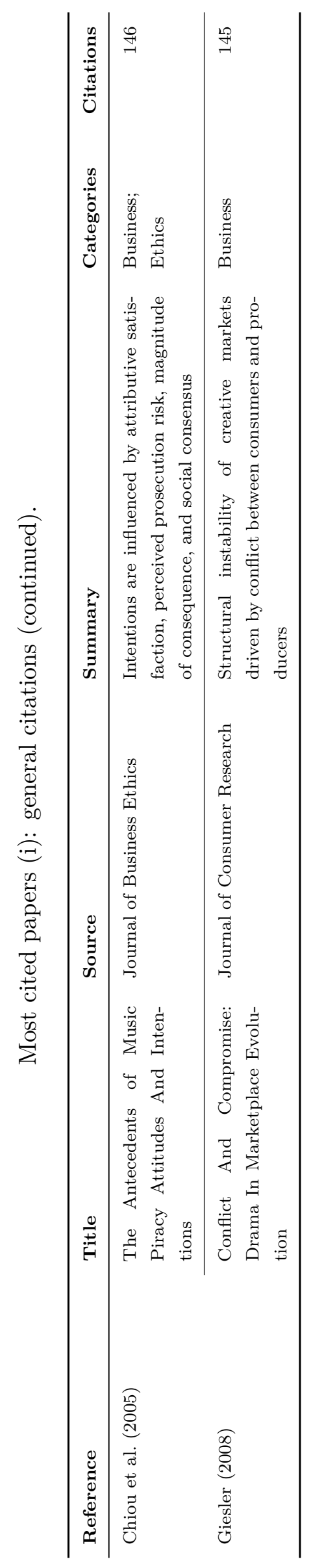




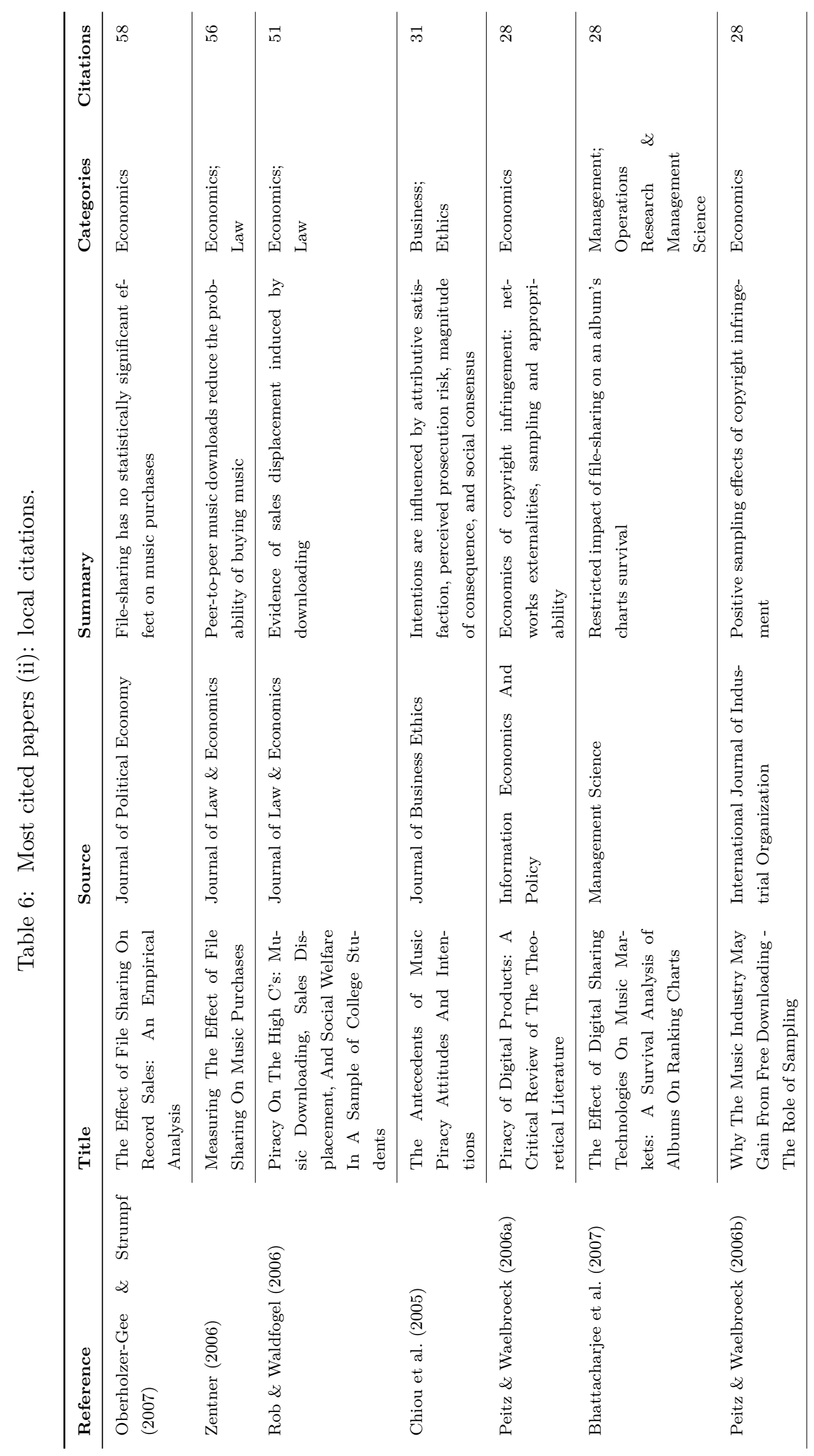




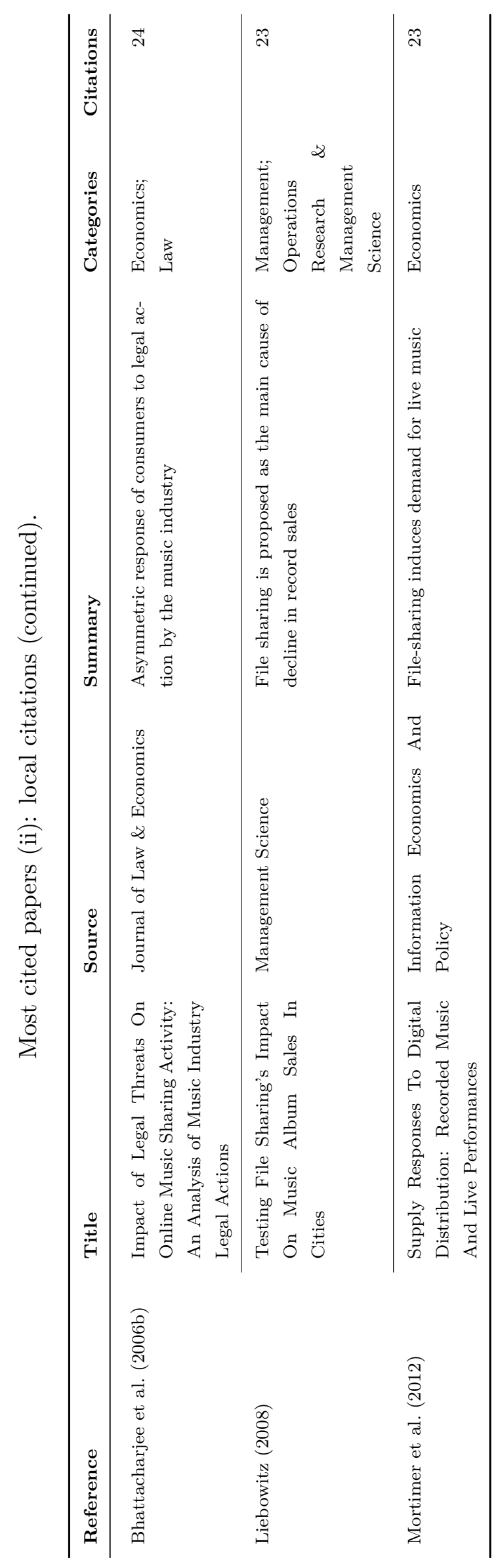




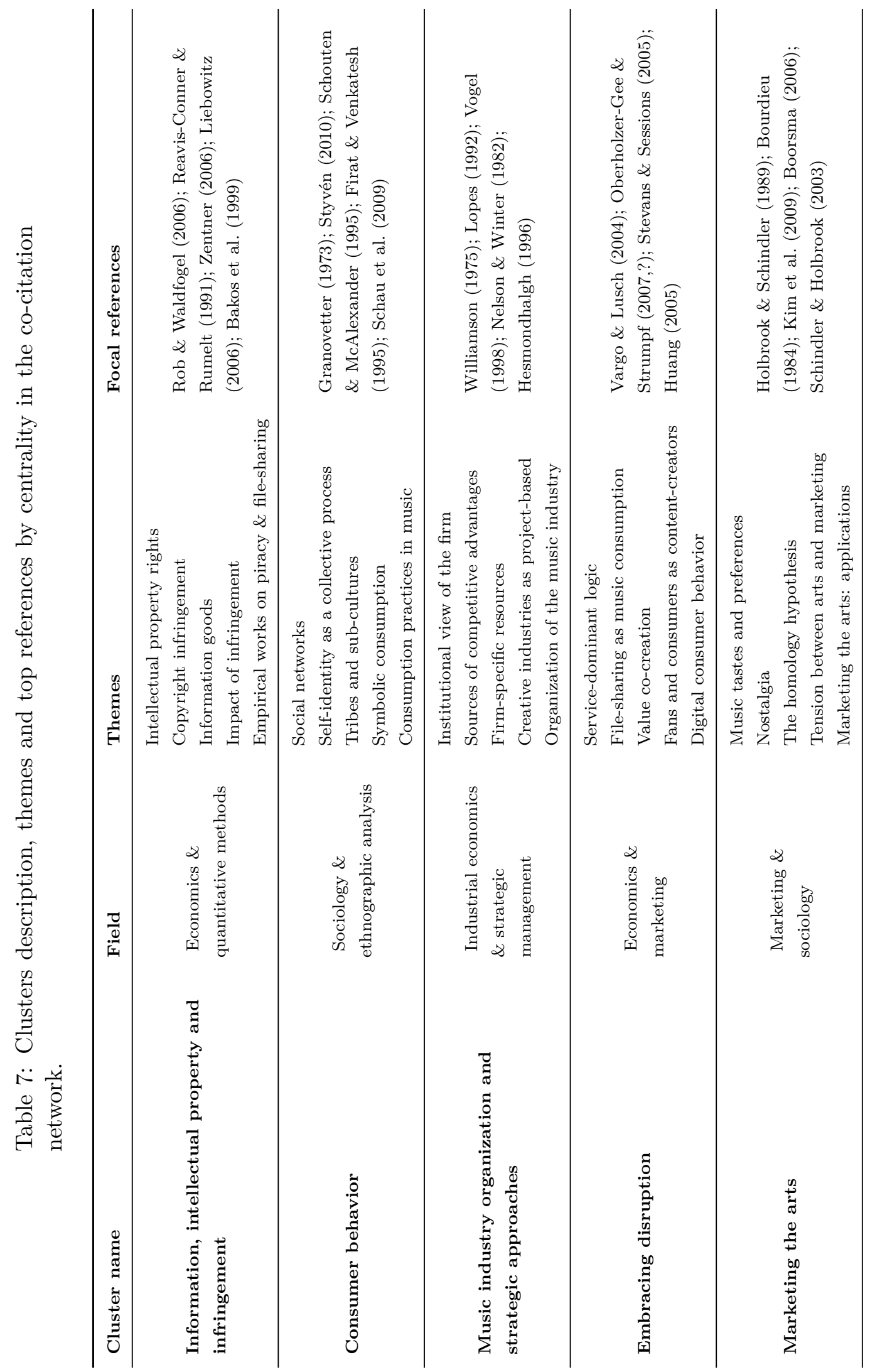




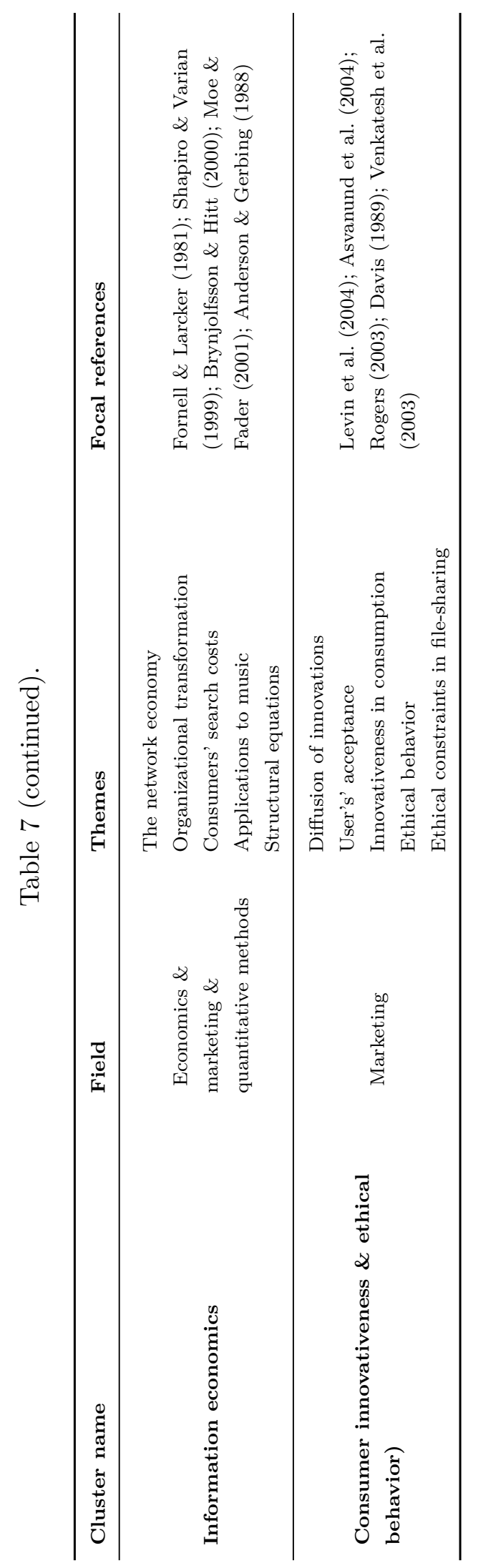




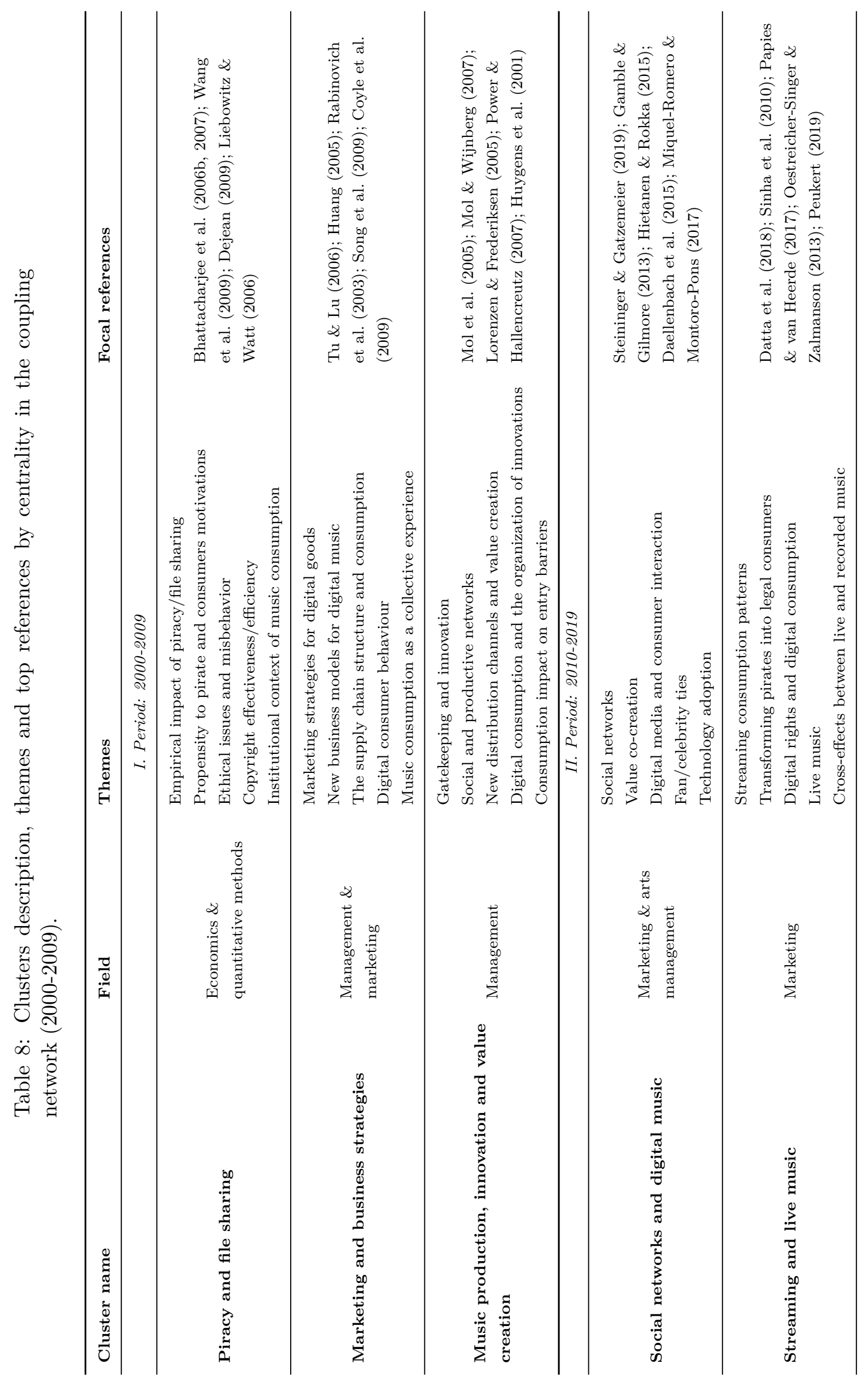




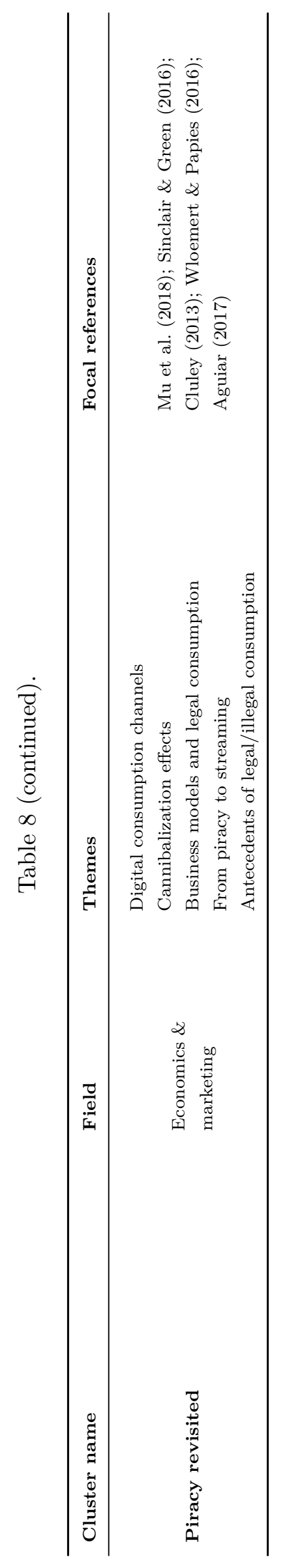




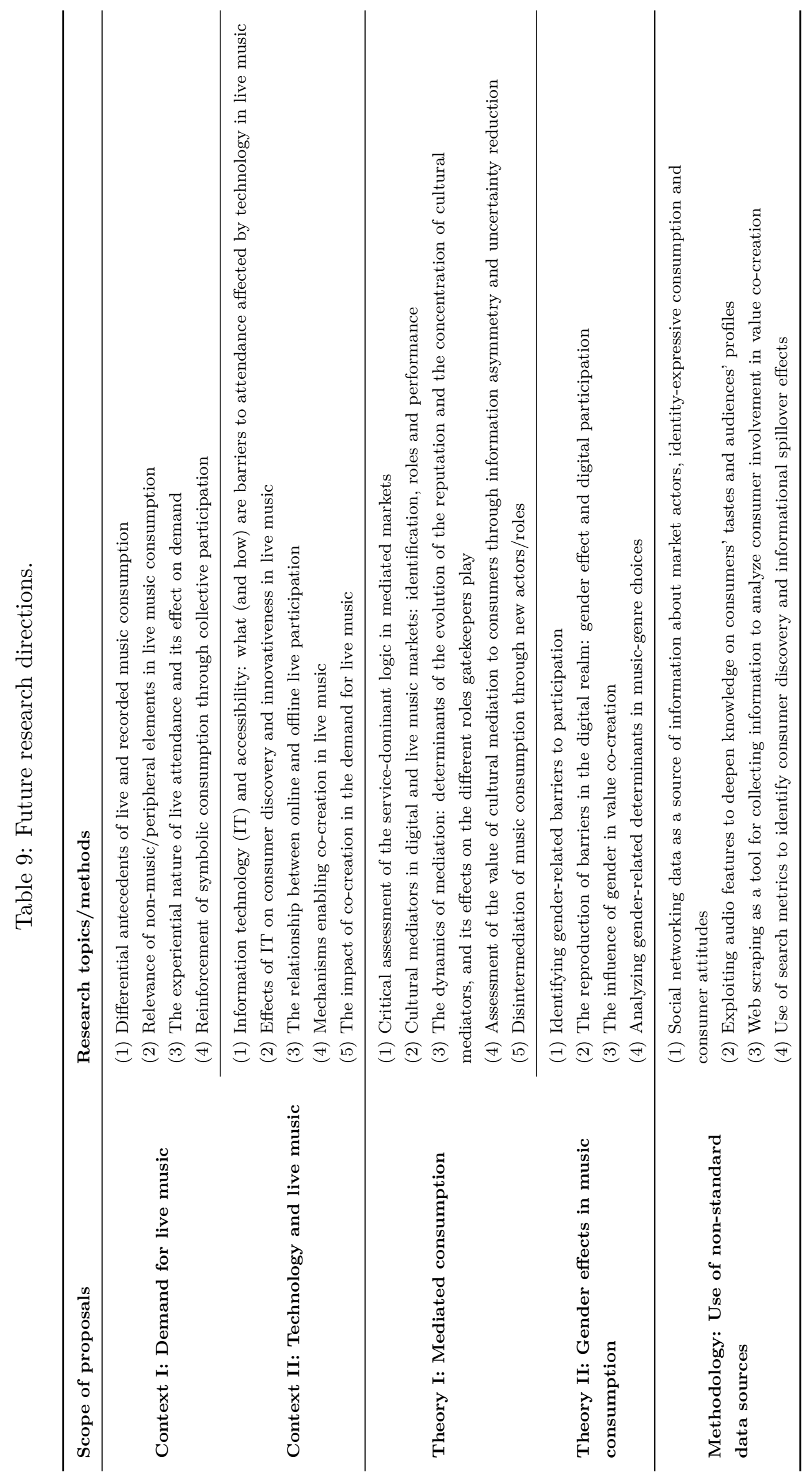




\section{Document selection}

Step 1. Identi cation and screening

Identi cation criteria:

- Source type: WoS/SSCI-indexed journal articles

- Language: English

- Search period: from 2000 to 2020

- WoS categories: business, economics and management

- Search keywords: see table 1

932 articles identi ed through database searching

Removal of one duplicate after screening: $\mathbf{n}=\mathbf{9 3 1}$

Step 2. Eligibility

Individual/collective review and discussion.

Exclusion criteria:

- Articles on the consumption/demand of content where music is not the topic of interest/analysis: 95 articles excluded

- Articles on the organization of music supply without explicit demand/consumption implications: 117 articles excluded

- Content not relevant (music as antecedent of behavior and/or marketing tool, e.g. consumer experience, servicescape...): 264 articles excluded

Total excluded: 476 articles

Articles meeting eligibility criteria $\mathbf{n}=\mathbf{4 5 5}$

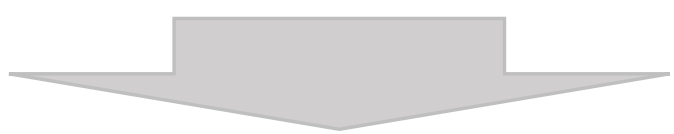

\section{Performance analysis}

Descriptive statistical summaries

- $\quad$ Include all articles meeting the eligibility criteria $\mathbf{n}=\mathbf{4 5 5}$

\section{Intellectual structure}

(a) Co-citation analysis

- Include articles in the top quartile of the citation distribution (23 or more) $\mathbf{n}=\mathbf{1 1 5}$

(b) Bibliographic coupling

- Collection split into two periods: 2000-2009 and 2010-2020

- Include articles with de ned publication year: $\mathbf{n = 4 5 2}$

\section{Conceptual structure}

\section{Co-word analysis and thematic map}

- Collection split into two periods: 2000-2009 and 2010-2020

- $\quad$ Include articles in the top quartile of the citation distribution ( 23 or more) $\mathbf{n}=\mathbf{1 1 5}$

Figure 1: Stages of the review process. 


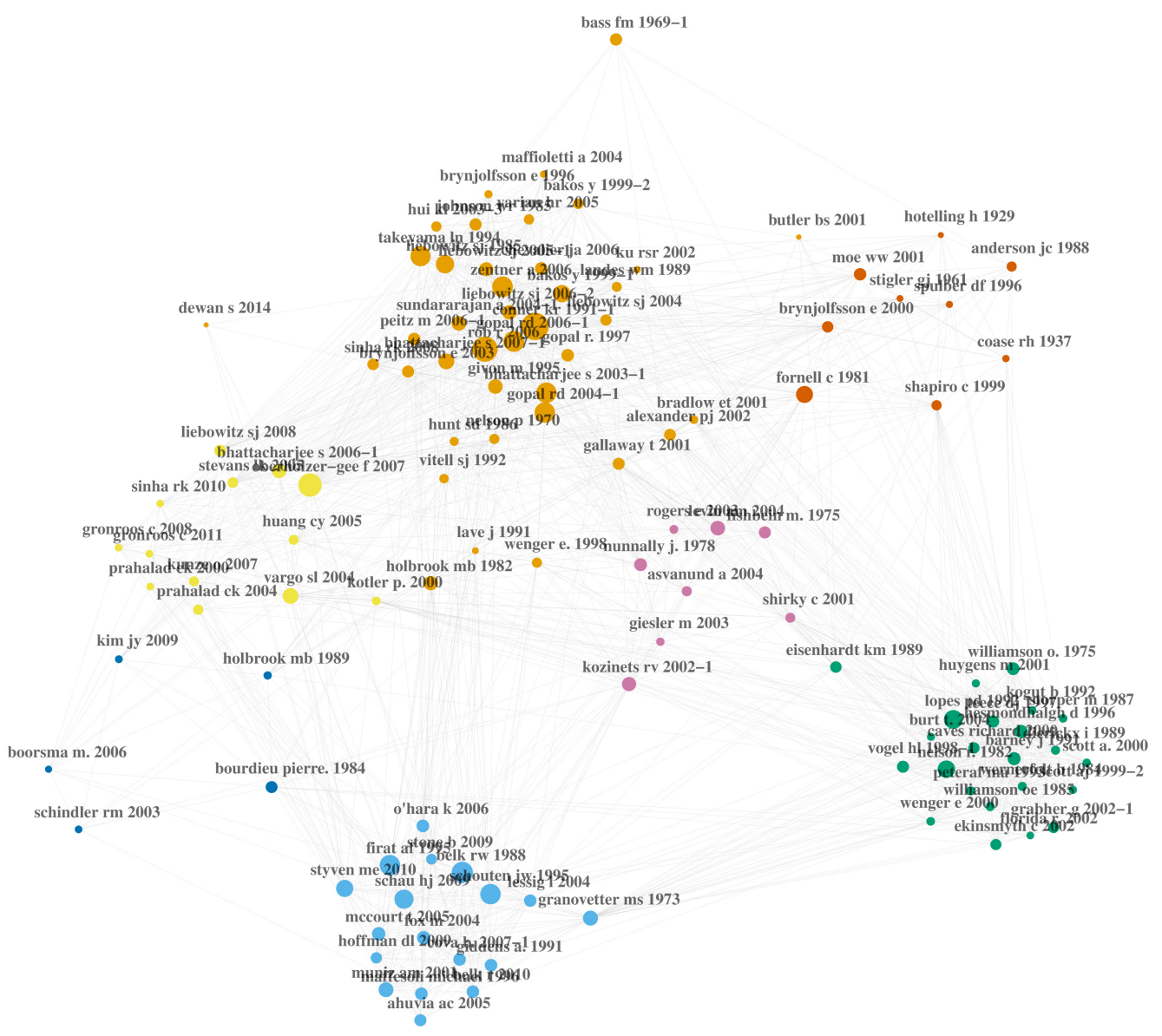

Figure 2: Co-citation network of focal papers. To improve readability only the labels for the most central nodes (top decile) are shown. 


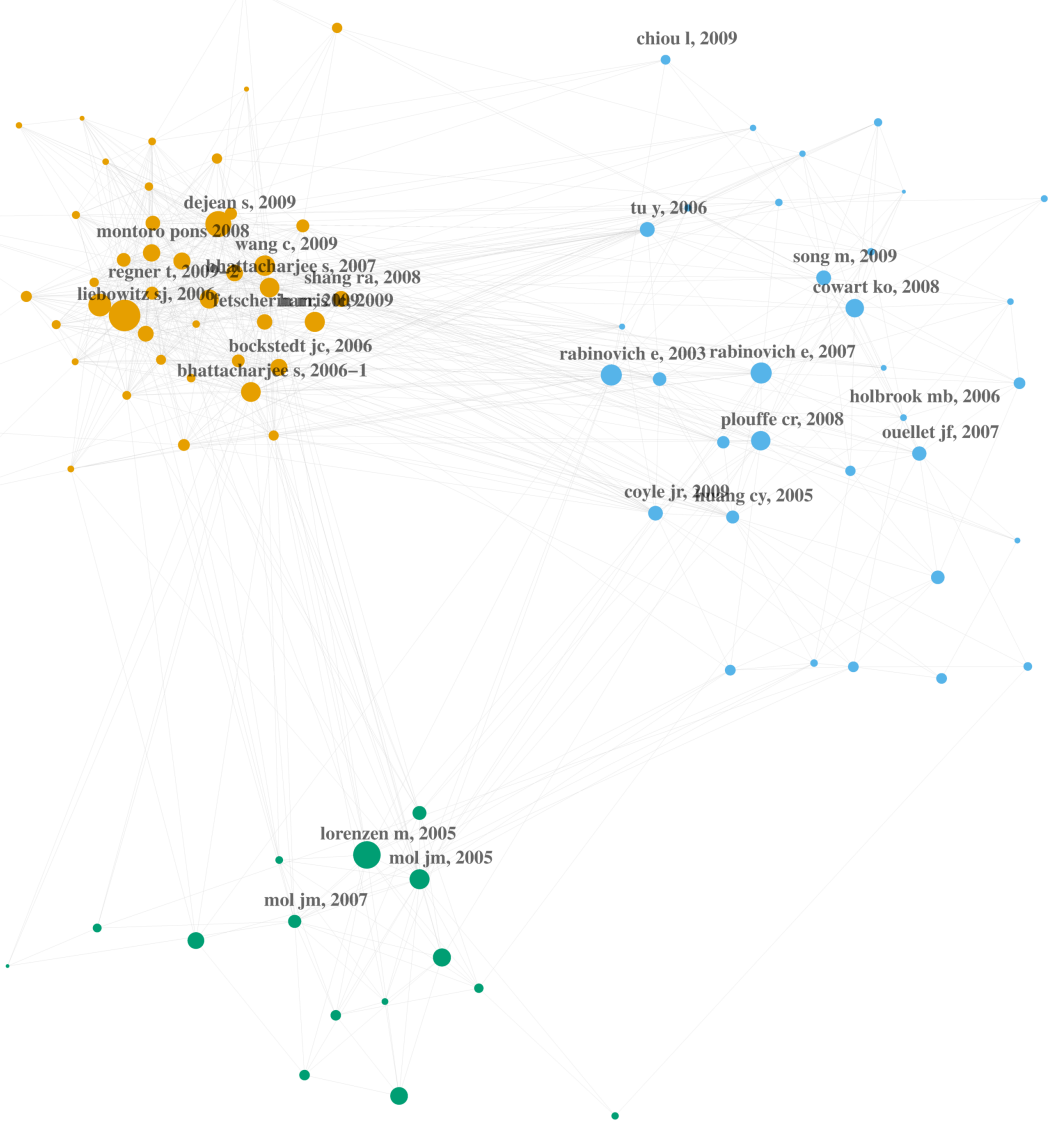

Figure 3: Coupling network: 2000-2009. To improve readability only the labels of the most central nodes are shown (top quartile). 

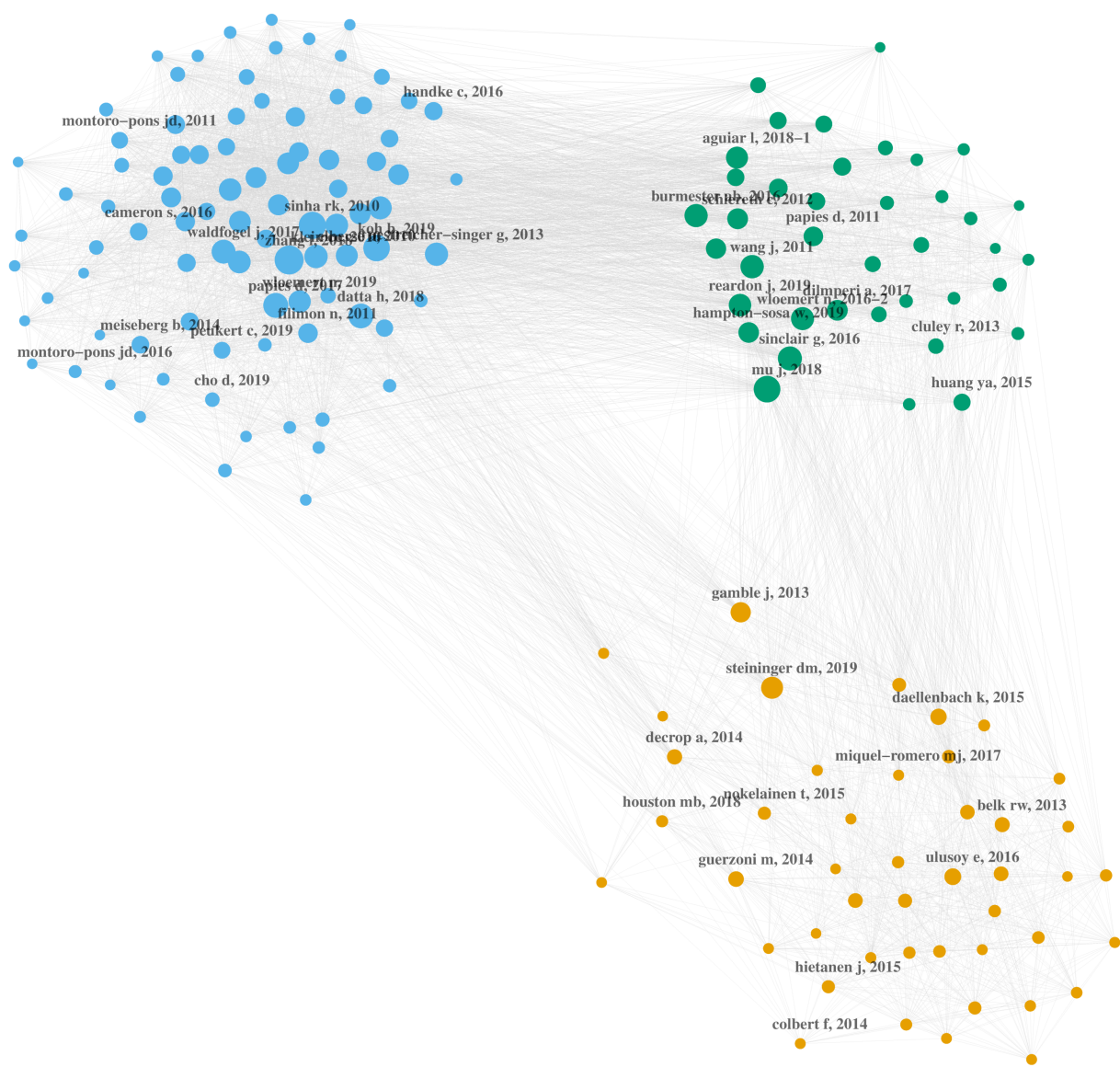

Figure 4: Coupling network: 2010-2020. To improve readability only the labels of the most central nodes are shown (top quartile). 


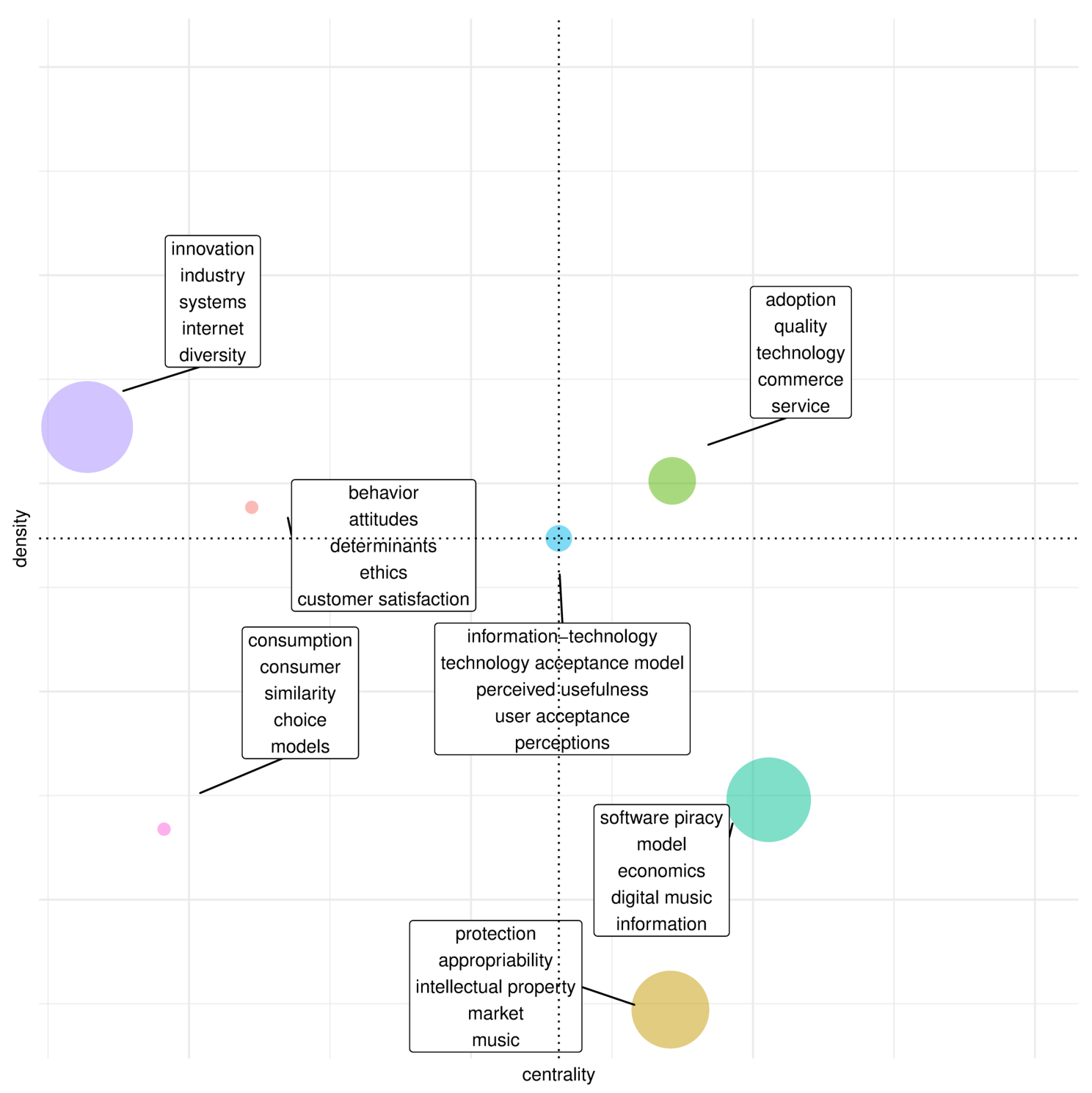

Figure 5: Thematic map of the top quartile papers (2000-2009) 


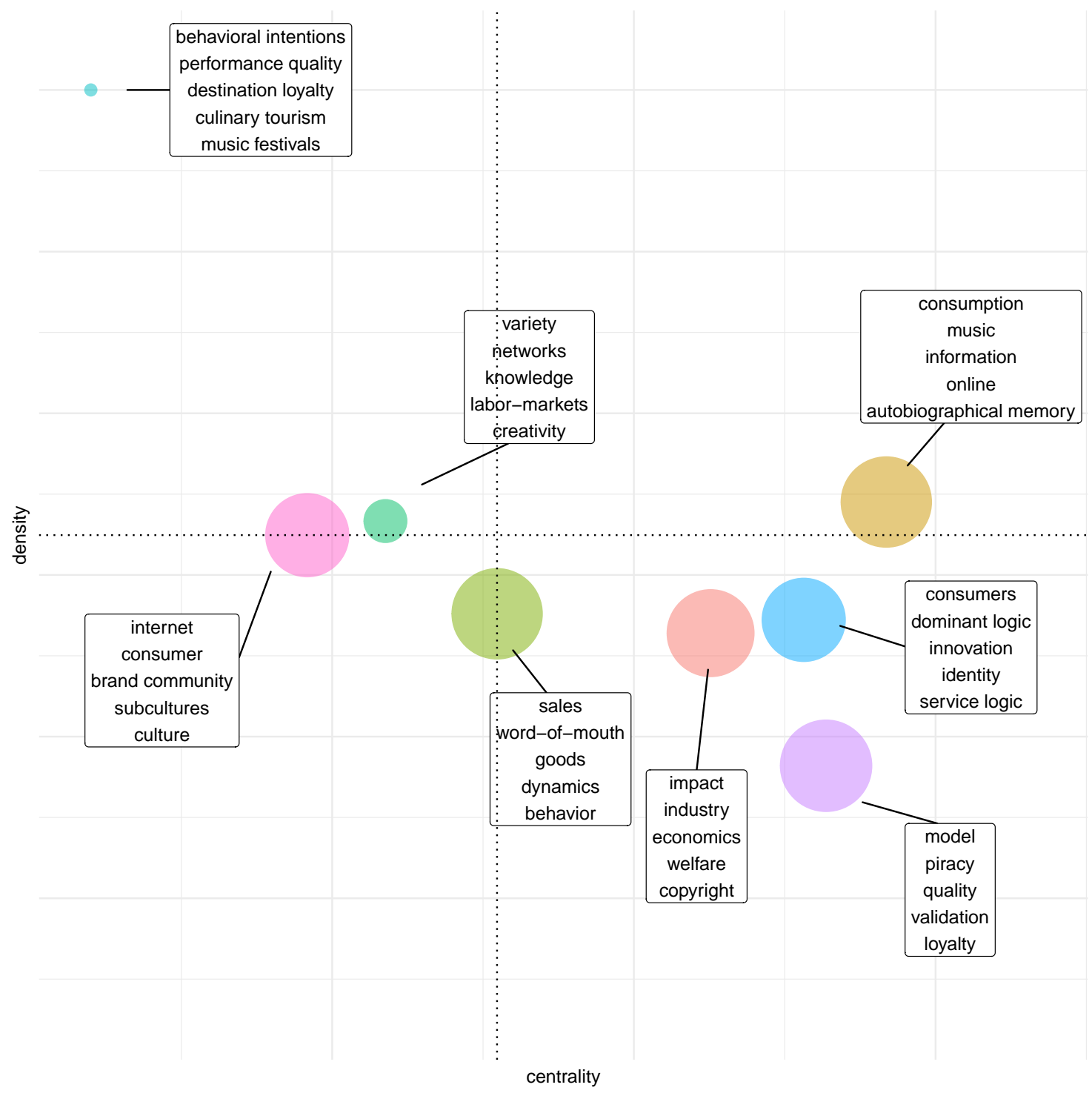

Figure 6: Thematic map of the top quartile papers (2010-2020) 